\title{
Overview of the JET results
}

\author{
F. Romanelli, on behalf of JET Contributors ${ }^{\mathrm{a}}$ \\ JET-EFDA, Culham Science Centre, OX14 3DB, Abingdon, UK \\ E-mail: francesco.romanelli@jet.efda.org
}

Received 25 November 2014, revised 12 January 2015

Accepted for publication 2 February 2015

Published 27 March 2015

\begin{abstract}
Since the installation of an ITER-like wall, the JET programme has focused on the consolidation of ITER design choices and the preparation for ITER operation, with a specific emphasis given to the bulk tungsten melt experiment, which has been crucial for the final decision on the material choice for the day-one tungsten divertor in ITER. Integrated scenarios have been progressed with the re-establishment of long-pulse, high-confinement H-modes by optimizing the magnetic configuration and the use of ICRH to avoid tungsten impurity accumulation. Stationary discharges with detached divertor conditions and small edge localized modes have been demonstrated by nitrogen seeding. The differences in confinement and pedestal behaviour before and after the ITER-like wall installation have been better characterized towards the development of high fusion yield scenarios in DT. Post-mortem analyses of the plasma-facing components have confirmed the previously reported low fuel retention obtained by gas balance and shown that the pattern of deposition within the divertor has changed significantly with respect to the JET carbon wall campaigns due to the absence of thermally activated chemical erosion of beryllium in contrast to carbon. Transport to remote areas is almost absent and two orders of magnitude less material is found in the divertor.
\end{abstract}

Keywords: JET, tokamaks, magnetic confinement

(Some figures may appear in colour only in the online journal)

\section{Introduction}

The European fusion programme is moving into the phase of implementation of its Roadmap [1] that foresees the use of JET in Horizon 2020 as the main risk-mitigation element for the preparation of ITER operation. In 2004 the JET programme in support of ITER was launched consisting of three main elements [2]: (i) the installation of an ITER-like wall (ILW) to reproduce the same material mix for the plasmafacing components (PFCs) of the nuclear phase of ITER; (ii) the development of plasma regimes of operation in the same configuration as ITER; and, (iii) a deuterium-tritium experiment to test the integrated regimes with the fuel mix of ITER. During the last couple of years, the ILW characterization has been almost completed. Significant progress has been made on scenario development and the preparation of the DT campaign has started.

In 2013 and 2014, JET carried out experimental campaigns in deuterium at plasma currents $I_{\mathrm{p}}$ up to $4 \mathrm{MA}$, magnetic field $B_{\mathrm{t}}$ up to $3.7 \mathrm{~T}$ and auxiliary power up to $P_{\mathrm{NBI}} \sim$ $27 \mathrm{MW}, P_{\mathrm{ICRH}} \sim 7 \mathrm{MW}, P_{\mathrm{LHCD}} \sim 3 \mathrm{MW}$. The upgraded components of the neutral beam system (the newly configured sources, the actively cooled ducts and the high voltage power supplies (HVPS)) have all separately achieved the design targets. However, problems with the old HVPS equipment and a major water leak in one injection box at the end of 2013 have prevented the achievement of the maximum neutral beam power needed for a full scenario optimization with the

${ }^{\text {a }}$ See the appendix
ILW at plasma currents beyond 2.5 MA. Nevertheless, after three years of operation with ILW (referred to in the following as the JET-ILW configuration) the JET heating systems have improved on the performance achieved with the carbon wall (the JET-C configuration) (figure 1) The JET experience with the ILW shows the need of a careful preparation (as now integrated in the ITER research plan with the choice of the $\mathrm{W}$ divertor from the start of ITER operation) and a proper real-time protection system for the PFCs in order to achieve continuous improvement in the plasma performance.

During this period, the ILW characterization has focused on the consolidation of the basis for the ITER decision on the first divertor [3,4] with a specific emphasis given to the bulk tungsten melt experiment to understand the effect of shallow melting due to transient events. For this purpose, a protruding divertor lamella has been installed in the most internal stack of the horizontal tile. A series of seven reproducible discharges produced shallow melting of tungsten and demonstrated the possibility of operating JET in these conditions without the occurrence of disruptions. The molten layer dynamics has been successfully modelled using the MEMOS code to validate the model and to allow a meaningful extrapolation to ITER. The results have been crucial for the final decision in favour of the tungsten divertor from the start of ITER operation.

In the first JET campaigns with the ILW [5-7] fuel retention and material migration studies had priority [8-11]. Now the focus of JET experiments has shifted towards integrated scenario development [12] to achieve low PFC heat loads [13-15] and avoid tungsten accumulation [16,17] with 

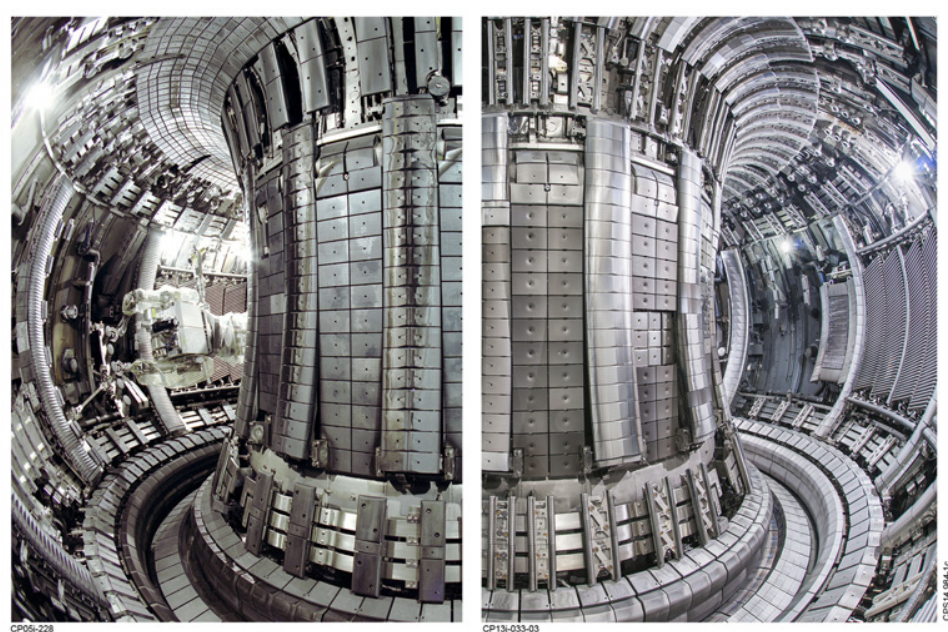

Figure 1. Picture of the interior of the JET vessel with an all carbon wall (JET-C) on the left and with the ITER-like wall (JET-ILW) with beryllium main chamber and tungsten divertor on the right.

the ultimate goal of achieving high performance plasmas [18, 19] in view of the DT experiment. Magnetic geometry, strike point location and divertor pumping were established as key aspects for achieving good H-mode confinement, leading to the re-establishment of long-pulse ( $\sim 9 s)$ highconfinement H-modes at 2.5 MA. This had to be combined with the control of tungsten accumulation by central heating using ion cyclotron resonant heating (ICRH) and sufficient gas fuelling. Significant effort was devoted to the use of impurity seeding [20] to produce core-divertor compatible scenarios which are essential for ITER, as well as high radiative scenarios which are required for DEMO. Stationary discharges have been produced by nitrogen seeding with fully detached divertor legs and small edge localized modes (ELMs). The use of Nseeding clearly increases the pedestal pressure but the global confinement is still $15 \%$ below the IPB98 $(y, 2)$ scaling.

Comparisons between baseline and hybrid plasmas have blurred the distinction between the two scenarios, which now appear on JET-ILW as a single operating domain. Dedicated power scans to elucidate the dependence on plasma beta of the energy confinement time have confirmed that on JET the power degradation is normally much weaker than the prediction of the IPB98 $(y, 2)$ scaling.

Post-mortem analyses of the PFCs retrieved from the first ILW campaigns [21-24] have confirmed the previously reported low fuel retention obtained by gas balance, with the measured deuterium inventory below $0.25 \%$ of the injected amount of deuterium (a factor 16 below that for the carbon wall). These studies show that the reduced material erosion and migration lead to reduced trapping of fuel in deposited beryllium layers which incorporate less fuel in comparison with carbon layers. In addition, the pattern of deposition within the divertor has changed significantly with the ILW in comparison with the JET carbon wall [25] due to the lower level of re-erosion. Transport to remote areas is almost absent, with the only significant beryllium deposits $(\sim 15 \mu \mathrm{m})$ found on the apron of the inner divertor. Overall, one order of magnitude lower deposition rate is found in the divertor compared to the carbon wall, with deposits in the floor of less than $2 \mu \mathrm{m}$ compared with more than $200 \mu \mathrm{m}$ thick deposits found after the last JET carbon-wall campaign due to long range migration via chemical erosion. These results are well reproduced by the WallDYN code. The WallDYN extrapolation to ITER shows a reduction in the retention by more than a factor ten and implies that at least 3000 full power DT discharges could be produced on ITER before reaching the T-inventory limit. This is comparable with the time estimated to obtain a substantial erosion of the divertor.

The investigation of effective runaway electron (RE) beam mitigation methods has continued. Spontaneous generation of REs is not normally observed in JET-ILW. Runaways can be generated through massive Ar injection and accelerated up to $20 \mathrm{MeV}$ with the production of runaway currents up to 1.2 MA. On JET, runaways can be suppressed by $\mathrm{D}_{2}$ injection provided injection takes place before the thermal quench. Thereafter, runaway suppression using high- $Z$ noble gases has been attempted but was found so far ineffective.

In section 2 we give an overview of all major results obtained with the ILW and the implications for ITER operation. In section 3 the development of ITER-relevant scenarios in the new all-metal environment is presented, along with confinement and edge pedestal physics results. Conclusions and perspectives are presented in section 4 .

\section{Operation of JET with the ILW}

\subsection{Bulk tungsten melt experiment}

A dedicated experiment has been carried out in JET to address the uncertainties associated with predicting the impact of transient tungsten melting in ITER due to ELMs [26-29]. The horizontal tile of the JET divertor is made of solid tungsten arranged in four stacks of lamellae in order to minimize the electromagnetic loads during disruptions (figure 2). JET's large size makes it possible to produce repetitive ELMs with sufficient energy $(\sim 300 \mathrm{~kJ}$ per ELM) to melt tungsten. Deliberate shallow tungsten melting has been produced by operating with the outer strike point on one protruding lamella, intentionally modified and installed in one divertor module on the innermost stack as shown in figure 2 [29]. A series of seven identical 3 MA discharges with 23 MW of heating power 




Figure 2. Schematic view of the lamella assembly in the modified stack.

were produced. Within $1 \mathrm{~s}$ the base temperature of the lamella was raised to a value well below the melting temperature, but sufficiently high to facilitate the shallow melting by ELMs with parallel power densities around $3 \mathrm{GW} \mathrm{m}^{-2}$ during a further $0.5 \mathrm{~s}$. The temperature on the top-side of the protruding and normal lamellae is measured by the infrared cameras. The top view does not allow resolved measurements on the side of the special lamella and this has made the interpretation more complex. The temperature measurements from the normal lamellae do not suffer the same problems and are used to deduce incident power fluxes as input for a 3D modelling of the heat transport through the special lamella with the exposed edge. The results are consistent with melting by ELMs followed by re-solidification of tungsten in between events. The melting produced an enhanced tungsten source with occasional expulsion of small droplets $(80-100 \mu \mathrm{m})$ which did not significantly impact the main plasma and caused no disruptions during the experiments or thereafter. Almost $1 \mathrm{~mm}$ depth (corresponding to a volume of $\sim 6 \mathrm{~mm}^{3}$ ) was moved/removed from the edge by several hundred ELMs during these pulses. The temperature of the special lamella is shown in figure 3 [30] and compared with that of a standard lamella. The analysis confirms that transient melting during the ELMs occurs and not bulk melting that continues across the ELM cycle. From photographic evidence it is possible to say that most of the molten tungsten moved along the lamella edge although a precise mass balance will be possible only after post-mortem analysis. The propagation of molten material is consistent with a $\mathbf{j} \times \mathbf{B}$ driving force, where $j$ is the current density into the surface (mainly due to thermoelectronic emission) and $B$ is the local magnetic field [31]. Droplets on the lamella were seen to coalesce and grow, which increases the risk for longer pulse duration above the melt threshold. Nevertheless, the consequences of melting had no significant impact on JET operation.

The inferred power load on the side of the JET special lamella was substantially lower than expected. In order to match the IR measurements, the tungsten evaporation rate inferred from the $\mathrm{W}_{\mathrm{I}} 400.88 \mathrm{~nm}$ line and the Planck radiation, the side heat loads must be reduced by a factor 2.5 in these $\mathrm{H}$-mode discharges (a larger reduction factor of about five is needed to match the measurements in L-mode). This result is not yet understood: simulations including the gyroradius smoothing effects predict only a $20 \%$ reduction [32],

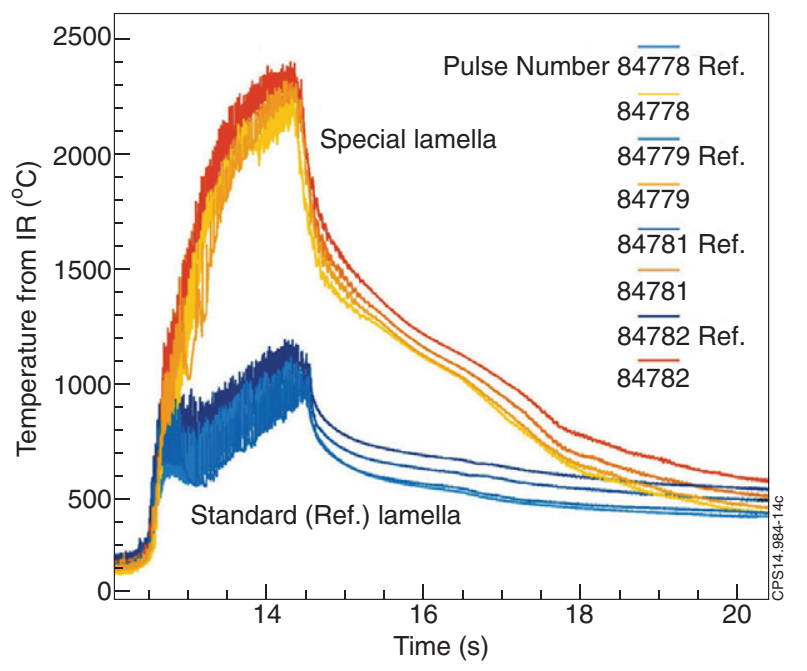

Figure 3. Temperature measurement for a few JET pulses used in the bulk tungsten melt experiment. Temperatures are shown for both the reference and the special lamella.

whereas the effect of vapour shielding may have contributed to the power load mitigation in H-mode where the surface temperature was near melting but could not explain the Lmode results where the surface is much colder. Although not understood, this finding has potentially positive implications for ITER, which may be less sensitive than previously feared to exposed edges created by chipping of mono-block edges or components outside tolerance.

JET results are consistent with simulations of tungsten melting and propagation using the MEMOS code [33], which has been used to inform decisions on the choice of tungsten as the material for the first divertor in ITER. The results have also given confidence that flash melting of the tungsten divertor elements by ELMs is relatively benign compared to bulk melting as reported in other experiments [34].

\subsection{Material erosion and migration, fuel recycling and retention}

The JET ILW experiment provided for the first time the opportunity to explore the coupling between tokamak plasma operation and plasma-surface interaction in the beryllium/tungsten material environment of ITER, complementing earlier experiments in other divertor tokamaks with metallic walls such as ASDEX Upgrade [35-39] and Alcator C-Mod [40-42]. These experiments are crucial in order to validate physics models and modelling tools for ITER with regard to material erosion and migration, fuel recycling and retention and impurity concentration and radiation.

The observed strong inter-connection of plasma-surface interaction with plasma-edge physics such as pedestal or divertor properties revealed that the impact of the first wall material on the plasma performance as well as the prominent role of chemical erosion of carbon in the main chamber and divertor was previously underestimated. The change in material migration with the JET-ILW can be seen as one key result as it impacts directly or indirectly on the majority of plasma-surface interaction processes mentioned above and contradicts partially the migration pattern predictions made 


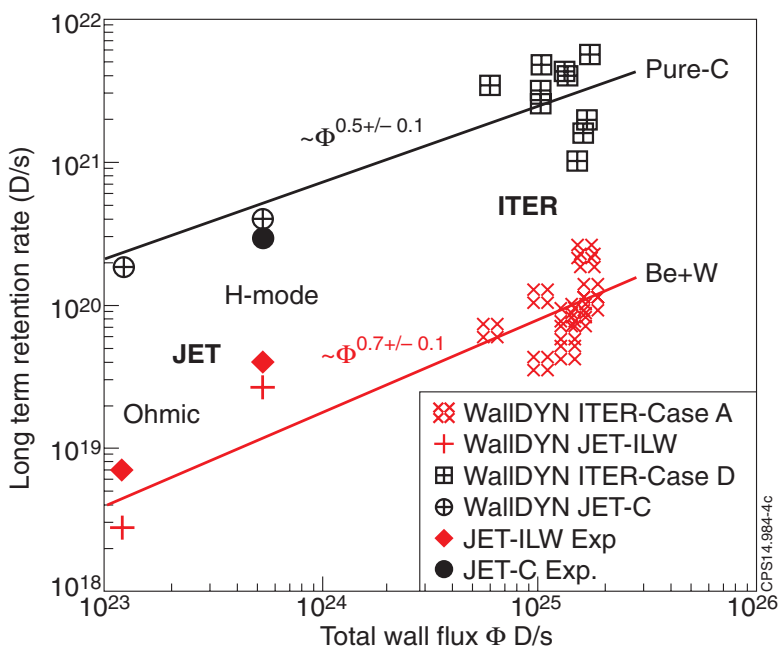

Figure 4. Long-term retention rate predictions for ITER made by WALLDYN [45].

for beryllium/tungsten PFCs on basis of migration physics deduced in JET-C including physical erosion characteristics of Be and W.

The primary source of Be sputtered in the Be main chamber wall is a factor of five lower than $\mathrm{C}$ sputtered in JET-C. The initial assumption that pure physical sputtering by energetic charge exchange neutrals is solely determining the main chamber source turned out to be invalid-low energetic ions reaching the first wall also sputtered chemically the $\mathrm{C}$ in JET-C. This chemical erosion at lowest energies $(10 \mathrm{eV})$ is absent due to energetic physical sputtering thresholds for $\mathrm{Be}-$ even if chemical assisted physical sputtering has been found for Be [43]. As consequence of the lower initial impurity source, the inner divertor is only partially covered by $\mathrm{Be}$ and indeed intact $\mathrm{W}$ surfaces are found. The local Be flux balance at the strike-line area is in favour of Be reflection and re-erosion and due to the low incoming flux not in deposition.

Furthermore, the virtual absence of chemical sputtering of beryllium inhibits the cycle of multiple erosion/deposition cycles within the divertor observed with carbon PFCs. Instead beryllium remains deposited at the positions where it lands after reflection or a physical sputtering process above the energetic threshold. It should be noted that, due to the low deposition rate and the limited operational time on JET, the JET-ILW migration pattern could represent an intermediate state with respect to long-pulse operation. This is supported by the fact that two orders of magnitude less dust were recovered compared with the carbon wall.

A special effort was made to accurately quantify the reduction in long-term fuel retention with the JET-ILW, already measured in gas balance experiments, through postmortem analysis. These results were used to validate the WallDYN code [44] and to allow a meaningful extrapolation to ITER. The code simulations reproduce both the reduction in fuel retention and the observed migration pattern. The remaining long-term retention is caused by implantation and co-deposition with beryllium and residual impurities. Shortterm retention gained relative importance with respect to the low level of long-term retention and impacts on the recycling properties of both beryllium and tungsten and local

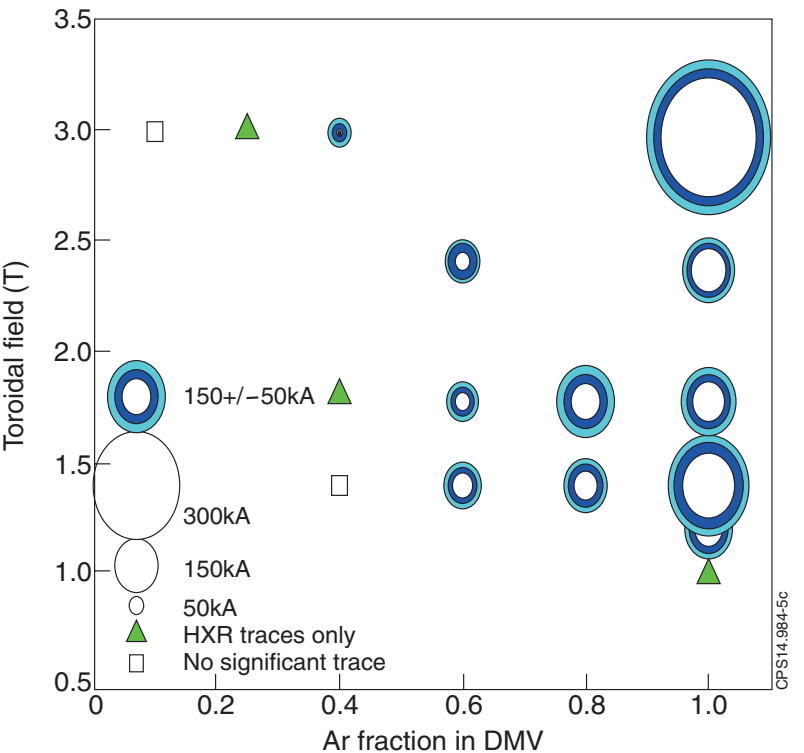

Figure 5. Operational domain for RE production in JET-ILW.

plasma properties. Predictions for ITER using WallDYN (figure 4) [45] indicate that more than 3000 full power DT discharges are possible before reaching the fuel-inventory limit, an amount comparable with that estimated for significant divertor erosion. If confirmed, the need of frequent fuel removal will be avoided.

\subsection{Disruptions and the generation of REs}

Successful disruption mitigation [46-48] with massive gas injection of a mixture of argon and deuterium has been obtained and is now mandatory for JET operation above 2 MA. The radiation efficiency of massive gas injection using the disruption mitigation valve (DMV) on JET (using a mixture of $90 \% \mathrm{D}_{2}+10 \% \mathrm{Ar}$ ) is $\geqslant 90 \%$ at a low thermal energy fraction $W_{\text {th }} / W_{\text {mag }}$ of $<0.3$ (where $W_{\text {th }}$ is the thermal energy and $W_{\text {mag }}$ is the magnetic stored energy), and reduces to $70 \%$ radiation efficiency at $W_{\mathrm{th}} / W_{\mathrm{mag}} \sim 0.5$. In these discharges the thermal stored energy was in the range $2.5-3 \mathrm{MJ}$. This behaviour is independent of the amount of injected impurities as long as the number of radiating atoms is above some limit. The radiated energy shows a clear toroidal asymmetry caused by a pre-existing locked mode. This asymmetry changes phase when the mode is locked in a $90^{\circ}$ rotated toroidal position. Massive gas injection into X-point and O-point of the lockedmode island results in strong changes of the toroidal radiation distribution. Future experiments with two DMVs will attempt to minimize the radiation asymmetry. It should be noted that typical values for the ratio $W_{\text {th }} / W_{\text {mag }}$ in ITER will be $W_{\text {th }} / W_{\text {mag }} \sim 0.9$. Hence, upgrades to the DMV systems are being made in JET to increase the gas delivery capability, at different locations, and with the capability to optimize the gas mixtures. Furthermore, experiments on JET are being planned at higher $W_{\mathrm{th}} / W_{\mathrm{mag}}$ values.

Although after the installation of the ILW REs [49, 50] are rarely generated during spontaneous disruptions, they can be generated, as in JET-C, using massive argon injection. Argon dominates the disruption plasma content, 




Figure 6. RE suppression by massive $\mathrm{D}_{2}$ injection. The injection is effective only if the injected gas reaches the plasma before the thermal quench (red). A delay of about $2 \mathrm{~ms}$ results in the production of a $850 \mathrm{kA}$ runaway beam.

as shown in figure 5 [51], thus decreasing the effect of the intrinsic impurities (carbon or beryllium) on the current quench dynamics. The conditions in which RE appear are similar between JET-C and JET-ILW: high toroidal field, high accelerating electric field and low densities (leading to lower critical electric field for RE generation) favour large RE currents. They also show a strong dependence on plasma initial shape and vertical stability.

Energies up to $20 \mathrm{MeV}$ were measured for 200 to $380 \mathrm{kA}$ RE beams. RE beams up to $1.2 \mathrm{MA}$ at $I_{\mathrm{p}}=2 \mathrm{MA}$ have been produced by massive argon injection via DMV, leading to substantial damage of tiles due to localized and toroidally asymmetrical melting on the inner wall and upper beryllium limiters [51]. It is to be noted that, within the uncertainty of the time reference of the IR camera, the interaction between the tile and the RE beam starts before the RE current decay, possibly due to contact with the wall. After in-vessel visual inspection, the affected tile showed clear signs of melting and droplet ejection over an area of about $10 \mathrm{~cm}^{2}$.

Suppression of fully developed runway beams up to 1.2 MA was attempted using massive high- $Z$ gas injections (up to 45 bar $1 \mathrm{Kr}$ or 24 bar $1 \mathrm{Xe}$ ). Although the fast camera showed that some gas arrived at the plasma, no useful mitigation was observed with no obvious change in hard ray emission or current decay rate. However, early massive deuterium injection was found to be efficient at totally suppressing the runaway beam provided that the gas reached the plasma before the mixing phase of plasma and incoming gas which occurs at the thermal quench (figure 6).

\section{H-mode physics in an all-metal environment}

The qualification of the ELMy H-mode and of the hybrid regime with the ILW has provided a number of results of direct
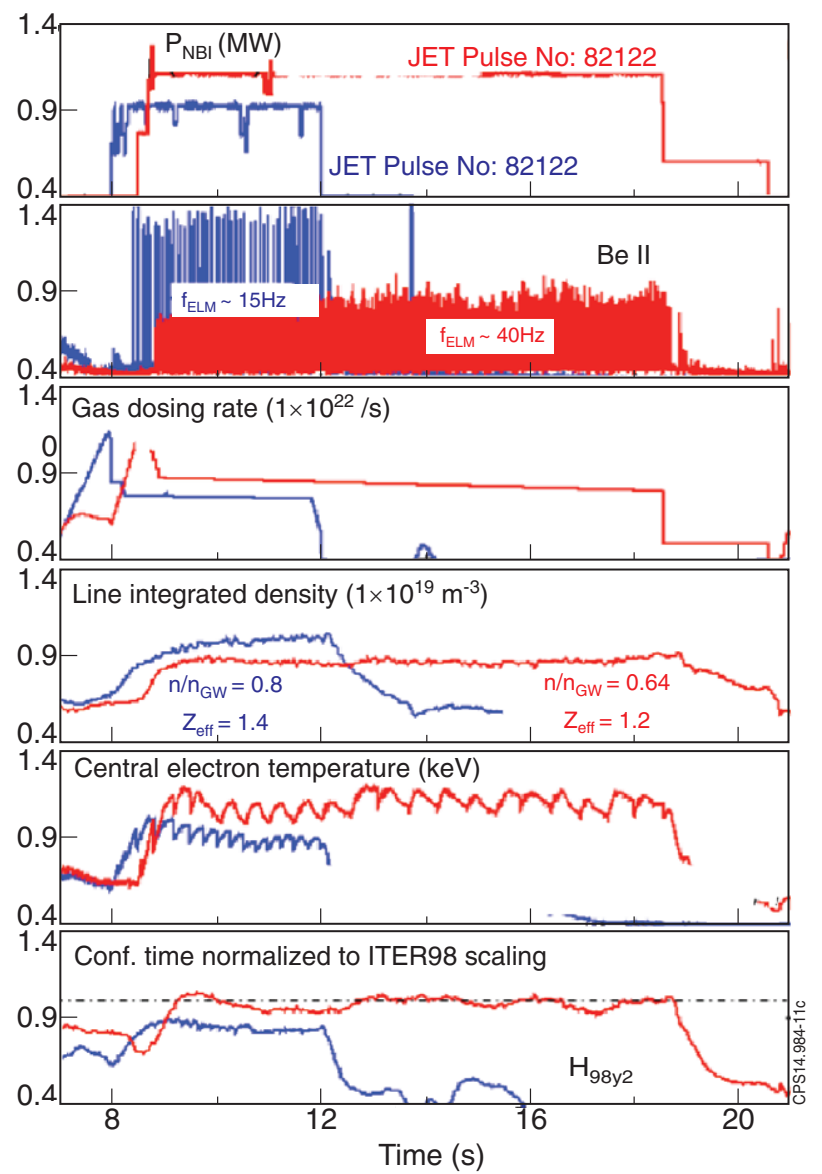

Figure 7. The optimization of the magnetic configuration led to the re-establishment of long-pulse, high-confinement H-modes (red). Shown in blue is the best discharge obtained in 2012 by controlled gas puffing to produce high-frequency ELMs and avoid W accumulation.

relevance for ITER. The baseline and hybrid scenarios have been progressed towards ITER dimensionless parameters in plasmas up to $4 \mathrm{MA}$, with $Z_{\text {eff }}$ values as low as 1.1 and the domain of good confinement extended [52]. High performance scenarios are being successfully developed within the ILW constraints, namely the control of heat loads on the PFCs, the minimization of core tungsten concentration and disruption mitigation/avoidance.

\subsection{Scenario development and optimization}

$\mathrm{H}$-mode and hybrid plasmas were obtained with energy confinement enhancement factors $\left(H_{98}\right)$ in the range of 0.9 1.2 [53] when compared with IPB98 $(y, 2)$ scaling law [54]. It was previously reported that stationary H-modes could be re-established with the ILW by avoiding W accumulation through the production of frequent ELM regimes by gas puffing [12]. This, however, had a detrimental effect on confinement, possibly due to the pedestal cooling by gas injection. During the last two years, stationary H-modes with confinement encompassing the ITER value $\left(H_{98}=1\right)$ have been produced by placing the divertor strike points such as to maximize pumping. In this way stationary, long-pulse ( $\sim 9 \mathrm{~s}) \mathrm{H}$-modes have been produced at low value of $Z_{\text {eff }}$ (figure 7). Interestingly, confinement times in line with or 


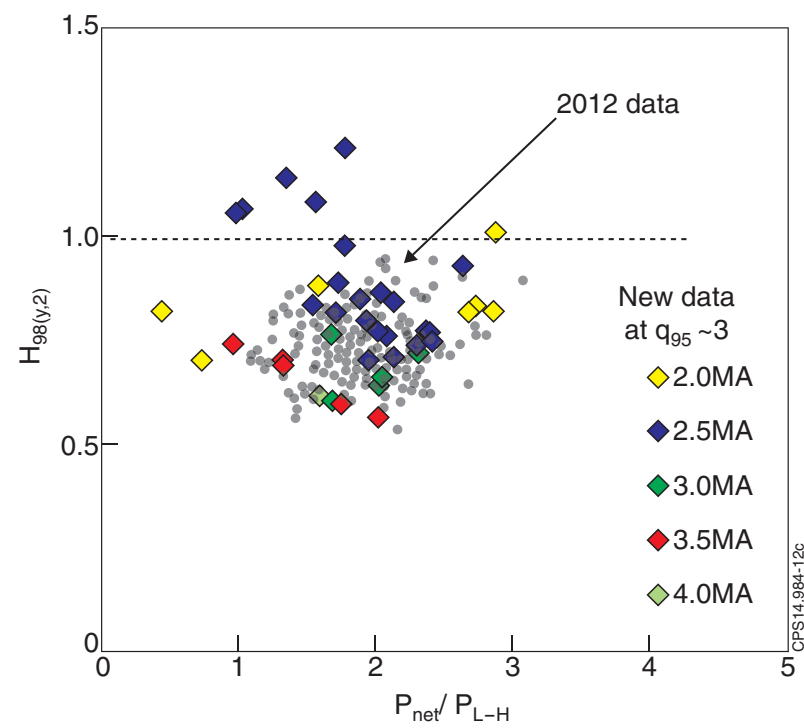

Figure 8. Achieved values of $H_{98}$ as a function of the ratio between the power conducted through the magnetic separatrix and the L-H threshold power in the baseline scenario. The grey circles are the 2012 data. Diamonds are the results of the last two years. Optimization has been carried out so far only at 2.5 MA.

above the ITER98 2 scaling have been obtained also for values of the ratio $P_{\text {net }} / P_{\mathrm{LH}}$ between 1 and 2, where $P_{\text {net }}$ is the power conducted through the separatrix and $P_{\mathrm{LH}}$ is the $\mathrm{LH}$ threshold power (figure 8).

Comparisons between baseline and hybrid plasmas in the range of $3 \leqslant q_{95} \leqslant 4.3$ and $1 \leqslant \beta_{\mathrm{N}} \leqslant 2.7$, for the same values of the toroidal magnetic field $\left(B_{\mathrm{T}}\right)$, plasma current $\left(I_{\mathrm{p}}\right)$, density $\left(n_{\mathrm{e}}\right)$ and heating power $\left(P_{\mathrm{NBI}}\right)$, have blurred the distinction between the two scenarios, which now appear as a single operating domain. Previously hybrid discharges at JET obtained $H_{98} \geqslant 1.1$ and $\beta_{\mathrm{N}} \geqslant 2.5$ for $q(0)$ just above or near 1, while baseline discharges were restricted to $H_{98}<1.1$ and $\beta_{\mathrm{N}}<2$ for fully diffused current profiles with $q(0)<1$. Recent experiments have shown that at lower input power (or beta) hybrid discharges obtain lower $\mathrm{H}_{98}$, while baseline discharges at high beta $\left(\beta_{\mathrm{N}} \geqslant 2.5\right)$ also have access to high confinement $\left(H_{98} \geqslant 1.1\right)$. Small differences between the two scenarios remain: ion temperature profiles are more peaked and neutron rates are higher in the hybrid scenario.

Power scans were performed under well-controlled conditions in the hybrid scenario in order to elucidate the validity of the power degradation included in the $\operatorname{IPB} 98(y, 2)$ scaling. The results confirmed earlier observations that the JET-ILW H-mode confinement time can be increased with respect to the $\operatorname{IPB} 98(y, 2)$ scaling as the heating power, or beta, is increased [55] consistent with previous observations of weak beta scaling of confinement in ELMy H-modes in DIII-D and JET [56]. The new experiments show weak power degradation of confinement when low gas injection rates are used to avoid the high-frequency ELMs discussed above. In these conditions the power exponent is found to be in the range -0.2 to -0.4 , as shown in figure 9 [57], as compared with -0.69 for the IPB98 $(y, 2)$ scaling. It should be noted that the JET-C high triangularity experiments were the only case, within these dedicated scans, to exhibit strong power degradation of confinement. It has been

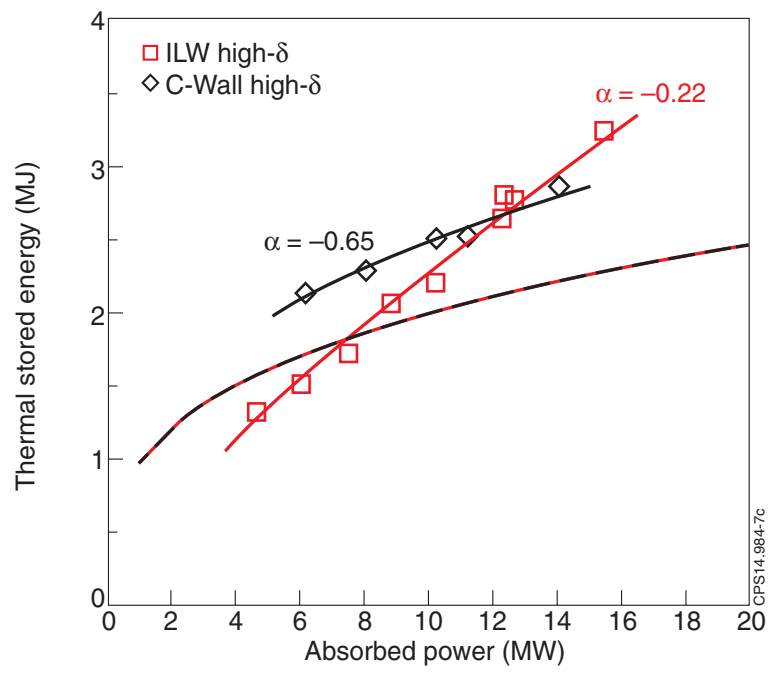

Figure 9. Plasma thermal stored energy as a function of absorbed heating power in the high triangularity configuration. The solid lines are fits to the data assuming a scaling of the form $W_{\text {th }} \sim P^{\alpha+1}$, where $\alpha$ is the exponent for the scaling for energy confinement time with power. The dashed line represents the dependence using the IPB98 $(y, 2)$ scaling (i.e. $\alpha=-0.69)$.

concluded [57] that these discharges are atypical of the confinement behaviour in JET in the controlled conditions of this experiment. This exceptional case appears to have been affected by variations in the neutral particle population in the main chamber [58], pointing out the role of neutral particles in plasma confinement [53]. This conclusion is supported by dedicated power scans in JET-ILW with higher gas injection rate, in which the observed confinement degradation with power is closer to the expectations of IPB98 $(y, 2)$. The strong increase in plasma stored energy with power in the JETILW H-mode with low gas injection is associated with the increase in pedestal pressure and core pressure peaking and may be due to the interplay of different mechanisms: (i) the temperature peaking increase is qualitatively consistent with previously proposed mechanisms relying on plasma rotation or supra-thermal ion pressure $[59,60]$; (ii) the correlation of density peaking with collisionality is consistent with previous observations and theory [61]; (iii) the increase in pedestal pressure with core plasma beta is consistent with modelling based on peeling-ballooning modes [62].

JET-ILW experiments confirmed also the importance of central electron heating for achieving high performance $\mathrm{H}$ modes in devices with high- $Z$ PFCs. ICRH has proven to be capable of mitigating core tungsten accumulation, in agreement with the expectation of neoclassical theory [63] in high power H-modes (with total auxiliary heating power $P_{\text {aux }}>20 \mathrm{MW}$ ) provided that the heating scenario is optimized and that the RF coupled power is high enough $\left(P_{\mathrm{RF}}>3 \mathrm{MW}\right)$, as shown in figure 10 [64]. Distributed main chamber gas injection (as opposed to the divertor gas fuelling usually adopted) achieved the best RF coupling, due to the increase of the local density in front of the ICRH antennas $[65,66]$. The ICRF absorption and core electron heating were optimised by fine-tuning the resonance position and the minority hydrogen concentration. The best results were obtained with central ICRF power deposition $(r<0.1 \mathrm{~m})$ 


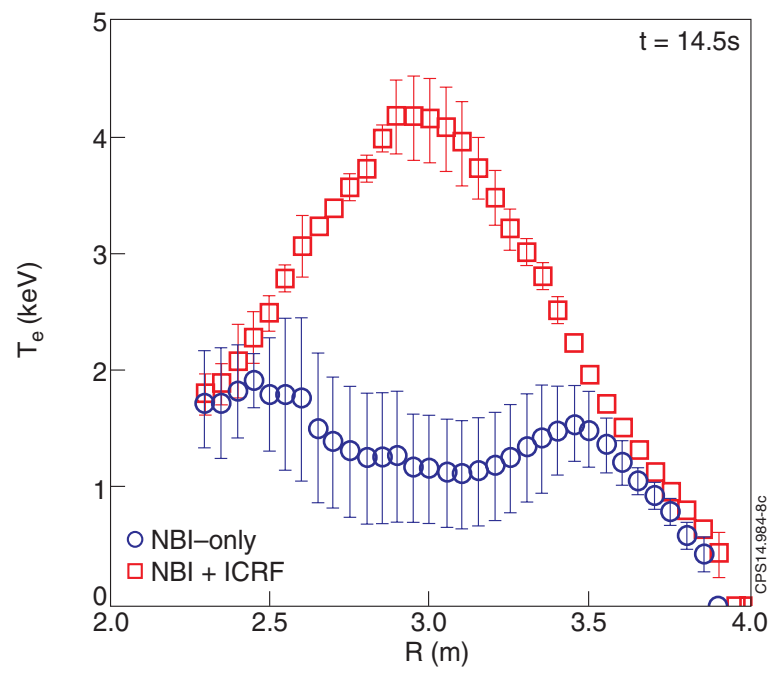

Figure 10. Comparison of the electron temperature profile at $t=54.5 \mathrm{~s}$ from the LIDAR diagnostic of two similar nitrogen-seeded discharges with NBI-only (JPN 85413) and NBI+ICRF (JPN 85412) with comparable total auxiliary power input.

and with low $\left(n_{\mathrm{H}} / n_{\mathrm{e}} \sim 5 \%\right)$ minority concentrations, both guaranteeing an efficient collisional transfer of the absorbed power to the electrons. A minimum ICRF power (4-5 MW) is necessary for achieving sufficiently peaked temperature profiles in typical H-mode plasmas at central densities $n_{\mathrm{e} 0}=$ $(7-9) \times 10^{19} \mathrm{~m}^{-3}$ for successful core impurity mitigation to take place. In most cases, a lower level (2-3 MW) is sufficient for avoiding radiative collapse.

\subsection{Core-edge integrated scenario development with impurity seeding}

Operational scenarios in ITER will require a significant fraction of the input/fusion power to be radiated $\left(f_{\text {rad }}>0.5\right)$ in order to generate tolerable PFC heat loads. This is even more important for DEMO, where it expected that $f_{\mathrm{rad}}>90 \%$ will be required. Demonstrating the combination of high radiation using extrinsic impurities with high fusion performance is thus an important part of developing integrated operating scenarios in JET and may be also needed in full performance JET discharges with a long steady-state phase. Stable discharges with radiation peaked around $\mathrm{X}$-point for have been obtained at JET using $\mathrm{N}_{2}, \mathrm{Ne}, \mathrm{Ar}$ and $\mathrm{N}_{2}+\mathrm{Ne}$ as seeding gasses. The maximum radiation achieved is $75 \%$ in all cases, and is independent of heating power over the range 14-28 MW. The physics reason for the limit at $75 \%$ radiation fraction is not yet understood [67]. In these conditions, tungsten concentrations are close to the detection limit and $\mathrm{H}$-mode discharges up to $10 \mathrm{~s}$ have been produced, although at reduced confinement.

Nitrogen seeding has also been shown to increase the pedestal pressure by up to $40 \%$ in high triangularity and $15 \%$ in low triangularity plasmas, restoring the confinement to a similar level to that seen with the carbon wall. Using $\mathrm{N}$ seeding, stationary condition over $7 \mathrm{~s}$ have been achieved on JET at 2.5 MA/2.7 T and $21 \mathrm{MW}$ input power with $\beta_{\mathrm{N}} \sim 1.6$, $\langle n\rangle / n_{\mathrm{GW}} \sim 0.85, Z_{\mathrm{eff}} \sim 1.6, f_{\mathrm{rad}} \sim 55 \%$, with low divertor target power loads and partial detachment between ELMs, as

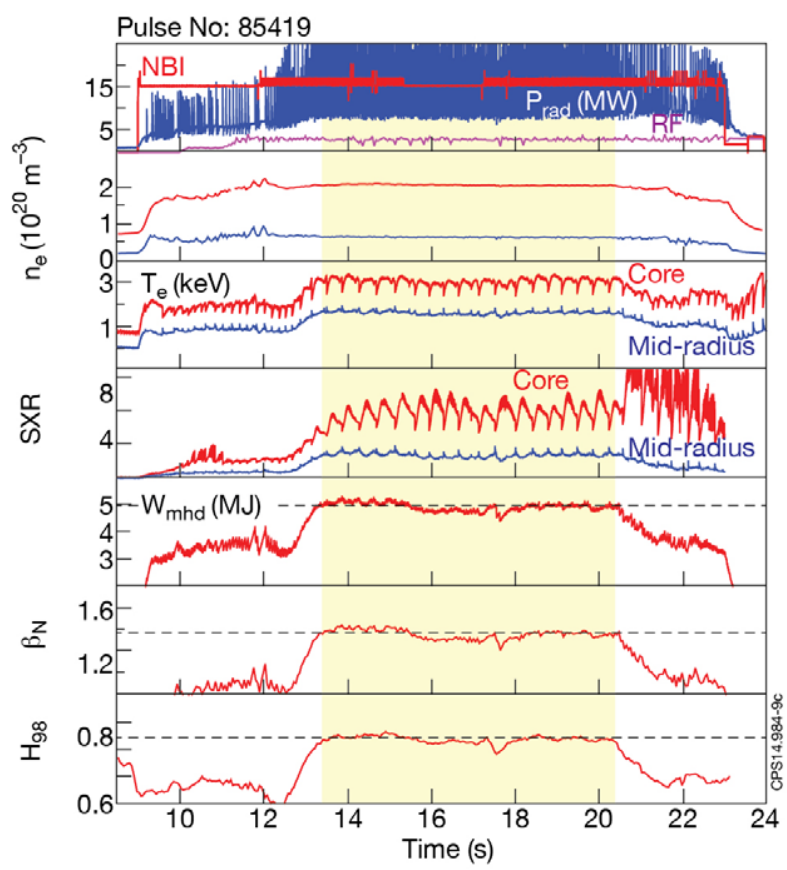

Figure 11. Time traces for long nitrogen-seeded pulse \#85419 at 2.5 MA/2.7 T showing avoidance of tungsten core accumulation in a high triangularity nitrogen-seeded plasma with VT divertor configuration by adding around $3 \mathrm{MW}$ of central ICRH heating power.

shown in figure 11 [68]. The performance of these plasmas is close to the desired ITER integrated plasma performance, in terms of Greenwald fraction, $Z_{\text {eff }}$, and divertor conditions, but the normalized energy confinement needs to be increased from $H_{98} \sim 0.85$ to $H_{98}=1$ and the ELM energy losses need to be lowered from $\sim 4 \%$ to less than $1 \%$ of the pedestal stored energy. Seeded plasma with partially detached divertor, $H_{98} \sim 1$ and $\beta_{\mathrm{N}} \sim 1.8$ will be a target of the next experimental campaign in which a higher level of input power should be available $\left(P_{\mathrm{aux}}>25 \mathrm{MW}\right)$.

\subsection{Progress towards maximum fusion performance}

Hybrid scenarios at high $\beta_{\mathrm{N}}$ were further progressed towards lower collisionality values $\left(v^{*} \sim 0.04\right)$, where better fusion performance is expected. In particular, a set of discharges with collisionalities low enough to match the upper range of the hybrid regimes in the JET carbon wall $\left(v^{*} \sim 0.04\right)$ for low triangularity plasmas $(\delta \sim 0.15)$ were achieved. These experiments used up to $25 \mathrm{MW}$ of NBI auxiliary power with $I_{\mathrm{p}}=2 \mathrm{MA}$ and $q_{95}=3.8$ using a configuration with the strike point on the outer horizontal tile for maximizing pumping, producing plasmas with $H_{98}$ up to 1.4 and $\beta_{\mathrm{N}}$ up to 3.4. Values of $\beta_{\mathrm{N}}$ up to 2.3 were achieved at $B_{\mathrm{T}}=2.9 \mathrm{~T}$ and $I_{\mathrm{p}}=2.5 \mathrm{MA}$ leading to a new neutron rate record of $2.3 \times 10^{16} \mathrm{~s}^{-1}$ for the ILW. The normalised confinement $H_{98}=1.15$ is consistent with the findings of the beta scan experiment and on the basis of the observed dependence of $H_{98}$ on $\beta_{\mathrm{N}}$, is expected to achieve higher values if the target $\beta_{\mathrm{N}}=2.5$ could be reached. The $\beta_{\mathrm{N}}$ value so far achieved is only limited by the available heating power. The duration (up to $3 \mathrm{~s}$ ) of the high performance phase is limited by impurity 
accumulation and MHD occurring during the accumulation process, requiring further optimization of divertor plasma conditions while maximizing core fusion performance.

The extrapolation of these discharges to a 50/50 DT fuel mix predicts that about $15 \mathrm{MW}$ of fusion power could be produced. This target could be achieved in stationary conditions for about $5 \mathrm{~s}$, rather than transiently as in the 1997 JET DT experiment, corresponding to a total produced fusion energy of $75 \mathrm{MJ}$, at $3.5 \mathrm{MA} / 3.45 \mathrm{~T}$ with $39 \mathrm{MW}$ of auxiliary power. These projections do not account for the contribution of the alpha particle heating and the beneficial isotope dependence of confinement, giving some margin in the achievable performance. In addition, recent analyses [69] of the 1997 record DT discharges show that core condition exceeding breakeven ( $Q=1$ with $Q$ evaluated from the power balance inside mid-radius) could have been already achieved in JET with core $Q$ values of about 1.5. Similarly, the extrapolated JET-ILW discharges are expected to achieve a higher core $Q$ value than that inferred by the global analysis. However, the scenario tailoring necessary to achieve divertorcompatible conditions represents a major area of required improvement for the next set of JET campaigns.

\section{4. $L-H$ transition studies}

JET-ILW experiments show a minimum in the L-H threshold power as function of density, as seen on other machines and on JET-C with the MkII-GB divertor, and a reduction of the threshold by $30 \%$ in the high-density branch. Both observations are potentially favourable for H-mode access on ITER [70,71]. Nitrogen injection increases the threshold to JET-C values, suggesting that the difference between JET-C and JET-ILW can be accounted for by the impurity composition. Experiments indicate that the density at which the minimum occurs depends on both impurity content and divertor configuration and was not accessible in JET-C with the current divertor. Changes to the magnetic configuration in the divertor lead to changes in $P_{\mathrm{L}-\mathrm{H}}$ up to a factor 2 . Fits of the edge density and temperature profiles show agreement with the assumption of a critical, diamagnetic driven, $E_{r}$ well (as proxy for the shearing rate) for each of the divertor configurations, but cannot explain the difference in $P_{\mathrm{L}-\mathrm{H}}$ between them. A transition that creates a strong inner-outer asymmetry in the divertor plasma conditions is observed with the same power scaling as the high-density branch of the $\mathrm{L}-\mathrm{H}$ threshold and precedes the $\mathrm{L}-\mathrm{H}$ transition at high density. This transition depends on the divertor configuration and hints at changes in the scrape-off layer directly affecting the transition.

\subsection{Pedestal studies with the ILW}

Pedestal studies have been carried out at JET with the main objective of addressing the physics responsible for the decrease in H-mode pedestal confinement observed in the initial phase of JET-ILW operation [61]. The effects of neutral recycling, plasma beta, plasma triangularity and nitrogen seeding on pedestal confinement and stability have been investigated, in the framework of the peeling-ballooning paradigm and making use of the EPED model [72]. It was found that low neutral recycling, achieved either by low deuterium gas injection rates or by divertor configurations with optimum pumping, and high beta are necessary conditions for good pedestal (and core) confinement. Under such conditions the pedestals are consistent with the peeling-ballooning paradigm. In contrast, under conditions characterized by high neutral recycling, additional physics is required in the pedestal model to explain the onset of the ELM instability. The physics mechanism leading to the increase in electron temperature in the pedestal with nitrogen seeding in high triangularity JET-ILW H-modes is not yet understood. The changes in edge confinement following the change in wall composition from $\mathrm{CFC}$ to beryllium/tungsten suggest the importance of the role of neutral recycling, low- $Z$ impurities and scrapeoff-layer physics in pedestal stability, elements that are not currently included in pedestal models. These aspects need to be addressed before a full predictive capability of the pedestal height can be achieved.

\section{Conclusions and perspectives}

Four years of JET operation with the ILW have provided confidence that the use of this combination of materials will not pose major problems for the successful operation of ITER. The low retention properties have been confirmed by the postmortem analysis and the melt layer experiment has shown that the consequence of melting can be tolerated for JET operation and that the JET results agree with the simulation codes that predict tolerable consequences also for ITER operation.

Significant progress has been made in expanding the domain in which good energy confinement is achieved by investigating magnetic configurations that allow a better pumping. Impurity seeding has been used to achieve steady regimes at high density and low $Z_{\text {eff }}$ with detached divertor.

Overall JET demonstrated successful plasma operation in the beryllium/tungsten material combination, confirmed its advantageous behaviour with respect to material migration and fuel retention and provided a strong scientific basis for the ITER material selection.

The ILW exploitation will continue in 2015 with the main aim of progressively increasing the plasma performance. In parallel, the preparation of a DT experiment is ongoing. The experiment is presently foreseen to take place in 2017 and according to the 'Reference Scenario' for the JET exploitation [1] will be followed by the machine being put in a safe state for decommissioning.

Following the completion of the feasibility studies for new JET enhancements, the design and R\&D activity for a set of internal resonant magnetic perturbation coils has been completed in collaboration with the Institute for Plasma Research in Gandhinagar. Its implementation on JET will require a decision on the 'Alternative Scenario' for the JET exploitation, consisting of the prolongation of JET up to 2022, tritium operation limited to a full-T experiment in 2017 and the DT experiment postponed to 2021.

\section{Acknowledgments}

The author acknowledges the support of D. Borba, G. Sips, L. Horton and of the JET Task Force Leaders and Deputy Task Force Leaders for the preparation of the manuscript. This work was supported by EURATOM and carried out within the 
framework of the European Fusion Development Agreement. The views and opinions expressed herein do not necessarily reflect those of the European Commission.

\section{Appendix: List of JET contributors}

M. Abhangi ${ }^{34}$, P. Abreu ${ }^{40}$, M. Aftanas ${ }^{37}$, M. Afzal ${ }^{3}$, K.M. Aggarwal ${ }^{20}$, L. Aho-Mantila ${ }^{94}$, E. Ahonen ${ }^{1}$, M. Aints ${ }^{90}$, M. Airila ${ }^{94}$, R. Albanese ${ }^{88}$, D. Alegre ${ }^{46}$, E. Alessi ${ }^{33}$, P. Aleynikov ${ }^{42}$, A. Alfier ${ }^{7}$ A. Alkseev ${ }^{55}$, P. Allan ${ }^{3}$, S. Almaviva ${ }^{79}$, A. Alonso ${ }^{46}$, B. Alper ${ }^{3}$, I. Alsworth ${ }^{3}$, D. Alves ${ }^{40}$, G. Ambrosino ${ }^{88}$, R. Ambrosino ${ }^{89}$, V. Amosov ${ }^{72}$, F. Andersson ${ }^{11}$, E. Andersson Sundén ${ }^{15}$, M. Angelone ${ }^{74}$, A. Anghel ${ }^{69}$, M. Anghel ${ }^{68}$, C. Angioni ${ }^{49}$, L. Appel ${ }^{3}$, G. Apruzzese ${ }^{74}$, P. Arena ${ }^{21}$, M. Ariola ${ }^{89}$, H. Arnichand ${ }^{4}$, G. $\operatorname{Arnoux}^{3}$, S. $\operatorname{Arshad}^{30}$, A. Ash ${ }^{3}$, E. Asp ${ }^{15}$, O. Asunta ${ }^{1}$, C.V. Atanasiu ${ }^{69}$, Y. Austin ${ }^{3}$, L. Avotina ${ }^{87}$, M.D. Axton ${ }^{3}$, C. Ayres $^{3}$, C. Bachmann ${ }^{25}$, A. Baciero ${ }^{46}$, D. Baião ${ }^{40}$, V. Bailescu ${ }^{71}$, B. Baiocchi ${ }^{4}$, A. Baker ${ }^{3}$, R.A. Baker ${ }^{3}$, I. Balboa $^{3}$, M. Balden ${ }^{49}$, N. Balshaw ${ }^{3}$, R. Bament ${ }^{3}$, J.W. Banks ${ }^{3}$, Y.F. Baranov ${ }^{3}$, I.L. Barlow ${ }^{3}$, M.A. Barnard ${ }^{3}$, D. Barnes ${ }^{3}$, R. Barnsley ${ }^{42}$, A. Baron Wiechec ${ }^{3}$, M. Baruzzo $^{7}$, V. Basiuk ${ }^{4}$ M. Bassan ${ }^{42}$, R. Bastow ${ }^{3}$ A. Batista ${ }^{40}$, P. Batistoni ${ }^{74}$, R. Bauer ${ }^{25}$, B. Bauvir ${ }^{42}$, B. Bazylev ${ }^{44}$, J. Beal ${ }^{92}$, P.S. Beaumont ${ }^{3}$, A. Becoulet ${ }^{4}$, P. Bednarczyk ${ }^{36}$, N. Bekris ${ }^{26}$, M. Beldishevski ${ }^{3}$, K. Bell ${ }^{3}$, F. Belli ${ }^{74}$, M. Bellinger ${ }^{3}$, J.K. Belo ${ }^{3}$, P. Belo ${ }^{3,40}$, É. Belonohy ${ }^{49}$, N.A. Benterman ${ }^{3}$, H. Bergsåker ${ }^{31}$, J. Bernardo ${ }^{40}$, M. Bernert $^{49}$, M. Berry ${ }^{3}$, L. Bertalot ${ }^{42}$, M.N.A. Beurskens ${ }^{3}$, B. Bieg ${ }^{36}$, J. Bielecki ${ }^{36}$, T. Biewer ${ }^{56}$, M. Bigi ${ }^{7}$, P. Bílková ${ }^{37}$, F. Binda ${ }^{15}$, J.P.S. Bizarro ${ }^{40}$, C. Björkas ${ }^{85}$, K. Blackman ${ }^{3}$, T.R. Blackman ${ }^{3}$, P. Blanchard ${ }^{23}$, E. Blanco ${ }^{46}$, P. Blatchford ${ }^{3}$, V. Bobkov ${ }^{49}$, A. Boboc ${ }^{3}$, G. Bodnár ${ }^{95}$, O. Bogar ${ }^{13}$, T. Bolzonella ${ }^{7}$, L. Boncagni ${ }^{74}$, R. Bonham ${ }^{3}$, G. Bonheure ${ }^{47}$, J. Boom ${ }^{49}$, J. Booth ${ }^{3}$, D. Borba ${ }^{26,40}$, D. Borodin ${ }^{29}$, A. Botrugno ${ }^{74}$, C. Boulbe ${ }^{45}$, P. Boulting ${ }^{3}$, K.V. Bovert ${ }^{29}$, M. Bowden ${ }^{3}$, C. Bower ${ }^{3}$, T. Boyce ${ }^{3}$, H.J. Boyer ${ }^{3}$, J.M.A. Bradshaw ${ }^{3}$, V. Braic $^{70}$, B. Breizman ${ }^{91}$, S. Bremond ${ }^{4}$, P.D. Brennan ${ }^{3}$, A. Brett ${ }^{3}$, S. Brezinsek ${ }^{29}$, M.D.J. Bright ${ }^{3}$, M. Brix ${ }^{3}$, W. Broeckx ${ }^{60}$, M. Brombin ${ }^{7}$, B.C. Brown ${ }^{3}$, D.P.D. Brown ${ }^{3}$, M. Brown ${ }^{3}$, E. Bruno ${ }^{42}$ J. Bucalossi ${ }^{4}$, J. Buch ${ }^{34}$, M.A. Buckley ${ }^{3}$, K. Bucko ${ }^{3}$, R. Budny ${ }^{59}$, H. Bufferand ${ }^{4}$, M. Bulman ${ }^{3}$, N. Bulmer ${ }^{3}$, P. Bunting ${ }^{3}$, P. Buratti ${ }^{74}$, G. Burcea ${ }^{71}$, A. Burckhart ${ }^{49}$, A. Buscarino ${ }^{21}$, P.R. Butcher ${ }^{3}$, N.K. Butler ${ }^{3}$, I. Bykov ${ }^{31}$, J. Byrne ${ }^{3}$, A. Byszuk ${ }^{36}$, A. Cackett ${ }^{3}$, P. Cahyna ${ }^{37}$, G. Cain $^{3}$, G. Calabrò ${ }^{74}$, C.P. Callaghan ${ }^{3}$, D.C. Campling ${ }^{3}$, J. Cane ${ }^{3}$, B. Cannas ${ }^{12}$, A.J. Capel ${ }^{3}$, M. Caputano ${ }^{88}$, P.J. $\mathrm{Card}^{3}$, A. Cardinali ${ }^{74}$, P. Carman ${ }^{3}$, D. Carralero $^{49}$, L. Carraro ${ }^{7}$, B.B. Carvalho ${ }^{40}$, I. Carvalho ${ }^{40}$, P. Carvalho ${ }^{40}$, F.J. Casson ${ }^{3}$, C. Castaldo $^{74}$, R. Cavazzana ${ }^{7}$, M. Cavinato ${ }^{7}$, A. Cazzaniga ${ }^{33}$, M. Cecconello ${ }^{15}$, E. Cecil $^{59}$, A. Cenedese $^{7}$, C. Centioli ${ }^{74}$, R. Cesario ${ }^{74}$, C.D. Challis ${ }^{3}$, M. Chandler ${ }^{3}$, D. Chandra ${ }^{34}$, C.S. Chang ${ }^{59}$, A. Chankin ${ }^{49}$, I.T. Chapman ${ }^{3}$, S.C. Chapman ${ }^{19}$, M. Chernyshova ${ }^{36}$, P. Chiru ${ }^{69}$, G. Chitarin ${ }^{7}$, B. Chouli ${ }^{4}$, N. Chung ${ }^{3}$, G. Ciraolo ${ }^{4}$, D. Ciric ${ }^{3}$, J. Citrin ${ }^{28}$, F. Clairet ${ }^{4}$, E. Clark ${ }^{3}$, D. Clatworthy ${ }^{3}$, R. Clay $^{3}$, M. Clever ${ }^{29}$, J.P. Coad ${ }^{3,94}$, P.A. Coates ${ }^{3}$, V. Coccorese ${ }^{88}$, V. Cocilovo ${ }^{74}$, S. Coda ${ }^{23}$, R. Coelho ${ }^{40}$, J.W. Coenen ${ }^{29}$, I. Coffey ${ }^{20}$, L. Colas ${ }^{4}$, S. Collins ${ }^{3}$, J.E. Conboy $^{3}$, S. Conroy ${ }^{15}$, N. Cook $^{3}$, D. Coombs ${ }^{3}$,
D. Cooper ${ }^{3}$, S.R. Cooper ${ }^{3}$, Y.Corre ${ }^{4}$, G. Corrigan ${ }^{3}$, S. Cortes ${ }^{40}$, D. Coster ${ }^{49}$, A.S. Couchman ${ }^{3}$, M. Cox ${ }^{3}$, M.P. $\mathrm{Cox}^{3}$, P. Cox ${ }^{3}$, T. Craciunescu ${ }^{69}$, S. Cramp ${ }^{3}$, F. Crisanti ${ }^{74}$, I. Cristescu ${ }^{44}$, G. $\mathrm{Croci}^{33}$, O. $\mathrm{Croft}^{3}$, K. Crombé ${ }^{10,47}$, R. Crowe ${ }^{3}$, N. Cruz ${ }^{40}$, G. $\mathrm{Cseh}^{95}$, K. Cull ${ }^{3}$, L. Cupido ${ }^{40}$, D. Curran ${ }^{80}$, M. Curuia ${ }^{68}$, A. Czarnecka $^{36}$, T. Czarski $^{36}$, S. Dalley ${ }^{3}$, A. Dalziel ${ }^{3}$, D. Darrow ${ }^{59}$, R. Davies ${ }^{3}$, W. Davis ${ }^{42,59}$, C. Day ${ }^{44}$, I.E. Day ${ }^{3}$, E. de la $\mathrm{Cal}^{46}$, E. de la $\mathrm{Luna}^{46}$, M. De Magistris ${ }^{88}$, J.L. de Pablos ${ }^{46}$, G. De Tommasi ${ }^{88}$, P.C. de Vries ${ }^{28}$, K. Deakin ${ }^{3}$, J. Deane ${ }^{3}$, J. Decker ${ }^{4}$, F. Degli Agostini ${ }^{7}$, R. Dejarnac ${ }^{37}$, E. Delabie ${ }^{28}$, N. den Harder $^{28}$, R.O. Dendy ${ }^{19}$, P. Denner ${ }^{29}$, S. Devaux ${ }^{49}$, P. Devynck ${ }^{4}$, F. Di Maio ${ }^{42}$, L. Di Pace ${ }^{74}$, T. Dittmar ${ }^{29}$, D. Dodt ${ }^{49}$, T. Donné ${ }^{25}$, P. Dooley ${ }^{6}$, S.E. Dorling ${ }^{3}$, S. Dormido-Canto ${ }^{77}$, S. Doswon $^{3}$, D. Douai ${ }^{4}$, P.T. Doyle ${ }^{3}$, T. Dreischuh ${ }^{35}$, P. Drewelow ${ }^{50}$, V. Drozdov ${ }^{3}$, K. Drozdowicz ${ }^{36}$, R. Dumont ${ }^{4}$, P. Dumortier ${ }^{47}$, D. Dunai ${ }^{95}$, M. Dunne ${ }^{80}$, I. Duran ${ }^{37}$, F. Durodié ${ }^{47}$,


P.V. Edappala ${ }^{34}$, A.M. Edwards ${ }^{3}$, Th. Eich $^{49}$, A. Ekedahl ${ }^{4}$, T. Elevant ${ }^{31}$, R. El-Jorf ${ }^{3}$, C.G. Elsmore ${ }^{3}$, G. Ericsson ${ }^{15}$, A. Eriksson ${ }^{11}$, J. Eriksson ${ }^{15}$, L.G. Eriksson ${ }^{27}$, B. Esposito ${ }^{74}$, H.G. Esser $^{29}$, D. Esteve ${ }^{4}$, G.E. Evans ${ }^{3}$, J. Evans ${ }^{3}$, G.D. Ewart ${ }^{3}$, D.T. Ewers ${ }^{3}$, D. Fagan ${ }^{3}$, D. Falie ${ }^{69}$, J.W. Farthing ${ }^{3}$, A. Fasoli ${ }^{23}$, L. Fattorini ${ }^{33}$, B. Faugeras ${ }^{45}$, J. Faustin ${ }^{23}$, N. Fawlk ${ }^{3}$, G. Federici ${ }^{25}$, N. Fedorczak ${ }^{4}$, R.C. Felton ${ }^{3}$, C. Fenzi $^{4}$, A. Fernades ${ }^{40}$, H. Fernandes ${ }^{40}$, J. Ferreira ${ }^{40}$, J.A. Fessey ${ }^{3}$, L. Figini ${ }^{33}$, A. Figueiredo ${ }^{40}$, J. Figueiredo ${ }^{26,40}$, A. Fil $^{4}$, P. Finburg ${ }^{3}$, M. Firdaouss ${ }^{4}$, U. Fischer ${ }^{4}$, L. Fittill ${ }^{3}$, M. Fitzgerald ${ }^{3}$, D. Flammini ${ }^{74}$, J. Flanagan ${ }^{3}$, C. Fleming ${ }^{3}$, K. Flinders ${ }^{3}$, A. Formisano ${ }^{61}$, L. Forsythe ${ }^{3}$, L. Fortuna ${ }^{21}$, M. Fortune ${ }^{3}$, M. Frasca ${ }^{21}$, L. Frassinetti ${ }^{31}$, M. Freisinger ${ }^{29}$, R. Fresa ${ }^{82}$, D. Frigione ${ }^{74}$, V. Fuchs ${ }^{37}$, J. Fyvie ${ }^{3}$, M. Gadomska ${ }^{25}$, K. Gál ${ }^{26,49}$, C. Galperti ${ }^{33}$, R. Galvão ${ }^{5}$, X. Gao ${ }^{38}$, S. Garavaglia ${ }^{33}$, J. Garcia ${ }^{4}$, A. Garcia-Carrasco ${ }^{31}$, M. García-Munoz ${ }^{49,76}$, M. Gardner ${ }^{3}$, L. Garzotti ${ }^{3}$, P. Gaudio ${ }^{79}$, E. Gauthier ${ }^{4}$, J.W. Gaze ${ }^{3}$, D.F. Gear ${ }^{3}$, S.J. Gee ${ }^{3}$, M. Gelfusa ${ }^{79}$, E. Genangeli ${ }^{74}$, S. Gerasimov ${ }^{3}$, G. Gervasini ${ }^{33}$, M. Ghate ${ }^{34}$, M. Gherendi ${ }^{69}$, J.C. Giacalone ${ }^{4}$, L. Giacomelli ${ }^{81}$, C.S. Gibson ${ }^{3}$, T. Giegerich ${ }^{44}$, D. $\mathrm{Gin}^{41}$, E. Giovannozzi ${ }^{74}$, J.B. Girardo ${ }^{4}$, C. Giroud ${ }^{3}$, G. Giruzzi ${ }^{4}$, C. Gleason-Gonzalez ${ }^{44}$, J. Godwin ${ }^{3}$, P. Gohil ${ }^{32}$, A. Gójska ${ }^{36}$, V. Goloborod' $\mathrm{ko}^{86}$, R. Gomes ${ }^{40}$, B. Gonçalves ${ }^{40}$, M. Goniche ${ }^{4}$, S. Gonzalez ${ }^{25}$, B. Goodsell ${ }^{3}$, A. Goodyear ${ }^{3}$, G. Gorini ${ }^{81}$, A. Goussarov ${ }^{60}$, B. Graham ${ }^{3}$, M.E. Graham ${ }^{3}$, J. Graves ${ }^{23}$, N. Grazier ${ }^{3}$, N.R. Green ${ }^{3}$, H. Greuner ${ }^{49}$, E. Grigore ${ }^{69}$, F.S. Griph ${ }^{3}$, C. Grisolia ${ }^{4}$, D. Grist ${ }^{3}$, M. Groth ${ }^{1}$, C.N. Grundy ${ }^{3}$, M. Gryaznevich ${ }^{66}$, D. Guard ${ }^{3}$, D. Gubb ${ }^{3}$, C. Guillemaut ${ }^{4}$, Y. Guo ${ }^{29}$, H.H. Utoh $^{43}$, L.J. Hackett ${ }^{3}$, S. Hacquin ${ }^{4}$, A. Hagar ${ }^{3}$, A. Hakola ${ }^{94}$, M. Halitovs ${ }^{87}$, S.J. Hall ${ }^{3}$, S.P. Hallworth Cook ${ }^{3}$, K. Hammond ${ }^{3}$, J. Hart ${ }^{3}$, D. Harting ${ }^{3,29}$, N. Hartmann ${ }^{29}$, T.D.V. Haupt ${ }^{3}$, N.C. Hawkes ${ }^{3}$, J. Hawkins ${ }^{3}$, P.W. Haydon ${ }^{3}$, S. Hazel ${ }^{3}$, P.J.L. Heesterman ${ }^{3}$, K. Heinola ${ }^{85}$, C. Hellesen ${ }^{15}$, T. Hellsten ${ }^{31}$, W. Helou ${ }^{4}$, O.N. Hemming ${ }^{3}$, T.C. Hender ${ }^{3}$, M. Henderson ${ }^{42}$, R. Henriques ${ }^{40}$, D. Hepple ${ }^{3}$, G. Hermon ${ }^{3}$, C. Hidalgo ${ }^{46}$, E.G. Highcock ${ }^{18}$, J.W. Hill ${ }^{3}$, M. Hill ${ }^{3}$, J. Hillairet ${ }^{4}$ J. Hillesheim ${ }^{3}$, D. Hillis ${ }^{56}$, A. Hjalmarsson ${ }^{15}$, J. Hobirk ${ }^{49}$, C.H.A. Hogben ${ }^{3}$, G.M.D. Hogeweij $^{28}$, D.A. Homfray ${ }^{3}$, J. Horáček ${ }^{37}$, A.R. Horton ${ }^{3}$, L.D. Horton ${ }^{27}$, S.P. Hotchin ${ }^{3}$, M.R. Hough ${ }^{3}$, P.J. Howarth ${ }^{3}$, A. Huber ${ }^{29}$, T.M. Huddleston ${ }^{3}$, M. Hughes ${ }^{3}$, C.L. Hunter ${ }^{3}$, 
H. Hurzlmeier ${ }^{25}$, S. Huygen ${ }^{47}$, P. Huynh ${ }^{4}$, J. Igitkhanov ${ }^{44}$, D. Iglesias ${ }^{3}$, M. Imríšek ${ }^{37}$, D. Ivanova ${ }^{31}$, I. IvanovaStanik $^{36}$, E. Ivings ${ }^{3}$, S. Jachmich ${ }^{26,47}$, A.S. Jacobsen ${ }^{66}$, P. Jacquet ${ }^{3}$, K. Jakubowska ${ }^{36}$, J. James ${ }^{3}$, F. Janky ${ }^{37}$, A. Järvinen ${ }^{1}$, F. Jaulmes ${ }^{28}$, S. Jednorog ${ }^{36}$, C. Jenkins ${ }^{3}$, I. Jenkins $^{3}$, K. Ješko ${ }^{37}$, E. Joffrin ${ }^{4}$, R. Johnson ${ }^{3}$, T. Johnson ${ }^{31}$, L. Joita ${ }^{3}$, G. Jones ${ }^{3}$, T.T.C. Jones ${ }^{3}$, L. Joyce ${ }^{3}$, C. Jupén ${ }^{16}$, K.K. Hoshino ${ }^{43}$, A. Kallenbach ${ }^{49}$, D. Kalupin ${ }^{25}$, K. Kamiya ${ }^{43}$, J. Kaniewski ${ }^{3}$, A. Kantor ${ }^{3}$, J. Karhunen ${ }^{1}$, G. Kasprowicz ${ }^{36}$, G. Kaveney ${ }^{3}$, Y. Kazakov ${ }^{47}$, D.L. Keeling 3 , J. Keep ${ }^{3}$, M. Kempenaars ${ }^{3}$, C. Kennedy ${ }^{3}$, D. Kenny ${ }^{3}$, E. Khilkevich ${ }^{41}$, M. Kiisk ${ }^{90}$, H.-T. Kim ${ }^{3}$, H.S. Kim ${ }^{62}$, C. King ${ }^{3}$, D. King ${ }^{3}$, R.F. King ${ }^{3}$, D.J. Kinna ${ }^{3}$, V. Kiptily ${ }^{3}$, K. Kirov ${ }^{3}$, A. Kirschner ${ }^{29}$, G. Kizane ${ }^{87}$, C. Klepper ${ }^{56}$, M. Knaup ${ }^{29}$, S.J. Knipe ${ }^{3}$, T. Kobuchi ${ }^{43}$, F. Köchl ${ }^{93}$, G. Kocsis ${ }^{95}$, D. Kogut ${ }^{4}$, S. Koivuranta ${ }^{94}$, M. Köppen ${ }^{29}$, T. Koskela ${ }^{1}$, H.R. Koslowski ${ }^{29}$, V. Kotov ${ }^{29}$, E. Kowalska-Strzęciwilk ${ }^{36}$, A. Krasilnikov ${ }^{72}$, V. Krasilnikov ${ }^{72}$, A. Kreter ${ }^{29}$, K. Krieger ${ }^{49}$, Y. Krivchenkov ${ }^{3}$, A. Krivska ${ }^{47}$, U. Kruezi ${ }^{3}$, I. Ksiazek ${ }^{36}$, A. Kukushkin ${ }^{55}$, A. $\mathrm{Kundu}^{34}$, T. Kurki-Suonio ${ }^{1}$, O.J. Kwon ${ }^{8}$, V. Kyrytsya ${ }^{47}$, M. Laan ${ }^{90}$, C. Labate ${ }^{6}$, L. Laguardia ${ }^{33}$, N. Lam ${ }^{3}$, C. Lane ${ }^{3}$, P.T. Lang ${ }^{49}$, J. Lapins ${ }^{87}$, A. Lasa ${ }^{85}$, J.R. Last ${ }^{3}$, A. Lawson ${ }^{3}$, K.D. Lawson ${ }^{3}$, A. $\operatorname{Lazaros}^{53}$, E. $\operatorname{Lazzaro}^{33}$, S. Lee ${ }^{52}$, H.J. Leggate ${ }^{22}$, M. Lehnen ${ }^{29,42}$, D. Leichtle ${ }^{30}$, P. Leichuer ${ }^{3}$, F. Leipold ${ }^{42}$, I. Lengar ${ }^{63}$, M. Lennholm ${ }^{27}$, E. Lerche ${ }^{47}$, M. Leyland ${ }^{92}$, W. Leysen ${ }^{60}$, Y. Liang ${ }^{29}$, J. Likonen ${ }^{94}$, V. Lindholm ${ }^{1}$, J. Linke ${ }^{29}$, Ch. Linsmeier ${ }^{29}$, B. Lipschultz ${ }^{51,92}$, X. Litaudon ${ }^{4,26}$, G. Liu $^{42}$, Y. Liu ${ }^{3,38}$, V.P. Lo Schiavo ${ }^{88}$, T. Loarer ${ }^{4}$, A. Loarte ${ }^{42}$, R.C. Lobel $^{3}$, N. Lohr ${ }^{44}$, P.J. Lomas ${ }^{3}$, J. Lönnroth ${ }^{1,26}$, J. López ${ }^{46}$, J. M. López ${ }^{78}$, F. Louche ${ }^{47}$, A.B. Loving ${ }^{3}$, S. Lowbridge ${ }^{3}$, C. Lowry $^{27}$, T. Luce ${ }^{32}$, R.M.A. Lucock ${ }^{3}$, A. Lukin ${ }^{57}$, A.M. Lungu ${ }^{69}$, C.P. Lungu ${ }^{69}$, I. Lupelli ${ }^{3}$, A. Lyssoivan ${ }^{47}$, P. Macheta ${ }^{3}$, A.S. Mackenzie ${ }^{3}$, G. Maddaluno ${ }^{74}$, G.P. Maddison ${ }^{3}$, B. Magesh ${ }^{34}$, P. Maget ${ }^{4}$, C.F. Maggi $^{49}$, H. Maier ${ }^{49}$, J. Mailloux ${ }^{3}$, A. Maj ${ }^{36}$, T. Makkonen ${ }^{1}$, R. Makwana ${ }^{34}$, A. Malaquias ${ }^{40}$, F. Mansffield ${ }^{3}$, M. Mansfield ${ }^{80}$, M.E. Manso ${ }^{40}$, P. Mantica ${ }^{33}$, M. Mantsinen ${ }^{2}$, A. Manzanares $^{75}$, Y. Marandet ${ }^{4}$, N. Marcenko ${ }^{72}$, C. Marchetto ${ }^{33}$ O. Marchuk $^{29}$, M. Marinelli ${ }^{79}$, M. Marinucci ${ }^{74}$, T. Markovič ${ }^{37}$, D. $\operatorname{Marocco}^{74}$, L. Marot ${ }^{64}$, C.A. Marren ${ }^{3}$, S. Marsen ${ }^{50}$, R. Marshal ${ }^{3}$, A. Martin ${ }^{3}$, D.L. Martin ${ }^{3}$, Y. Martin ${ }^{23}$, A. Martín de Aguilera ${ }^{46}$, J.R. Martín-Solís ${ }^{9}$, A. Masiello ${ }^{7}$, M. Maslov ${ }^{3}$, V. Maslova ${ }^{3}$, S. Matejcik ${ }^{13}$, M. Mattei ${ }^{61}$, G.F. Matthews ${ }^{3}$, D. Matveev ${ }^{10}$, M. Matveev ${ }^{29}$, F. Maviglia ${ }^{6,25}$, M. Mayer ${ }^{49}$, M.-L. Mayoral ${ }^{25}$, D. Mazon ${ }^{4}$, C. Mazzotta ${ }^{74}$, R. McAdams ${ }^{3}$, P.J. McCarthy ${ }^{80}$, K.G. McClements ${ }^{3}$, K. McCormick ${ }^{49}$, P.A. McCullen ${ }^{3}$, D. McDonald ${ }^{25}$, R. Mcgregor ${ }^{3}$, R. McKean $^{3}$, J. McKehon ${ }^{3}$, R. McKinley ${ }^{3}$, I. Meadows ${ }^{3}$, R.C. Meadows ${ }^{3}$, F. Medina ${ }^{46}$, M. Medland ${ }^{3}$, S. Medley ${ }^{3}$, S. Meigh ${ }^{3}$, A.G. Meigs ${ }^{3}$, L. Meneses ${ }^{40}$, S. Menmuir ${ }^{31}$, I.R. Merrigan ${ }^{3}$, Ph. Mertens ${ }^{29}$, S. Meshchaninov ${ }^{72}$, A. Messiaen ${ }^{47}$, B. Meszaros $^{25}$, H. Meyer ${ }^{3}$, G. Miano ${ }^{88}$, R. Michling ${ }^{42}$, D. Middleton-Gear ${ }^{3}$, J. Miettunen ${ }^{1}$, P. Migliucci ${ }^{79}$, E. MilitelloAsp $^{3}$, S. Minucci ${ }^{88}$, F. Mirizzi ${ }^{74}$, Y. Miyoshi ${ }^{43}$, J. Mlynár ${ }^{37}$, I. Monakhov ${ }^{3}$, P. Monier-Garbet ${ }^{4}$, R. Mooney ${ }^{3}$, S. Moradi ${ }^{24}$, S. Mordijck $^{32}$, L. Moreira ${ }^{3}$, R. Moreno ${ }^{46}$, P.D. Morgan ${ }^{3}$, R. Morgan $^{3}$, L. Morley ${ }^{3}$, C. Morlock ${ }^{25}$, A.W. Morris ${ }^{3}$, J. Morris ${ }^{3}$, L. Moser ${ }^{64}$, D. Moulton ${ }^{1}$, A. Murari ${ }^{7}$, A. Muraro ${ }^{33}$, I. Mustata ${ }^{69}$, N.N. Asakura ${ }^{43}$, F. Nabais ${ }^{40}$, T. Nakano ${ }^{43}$, E. Nardon ${ }^{4}$, V. Naulin ${ }^{66}$, M.F.F. $\mathrm{Nave}^{40}$, I. Nedzelski ${ }^{40}$,
N. Neethiraj ${ }^{3}$, G. Nemtsev $^{72}$, F. Nespoli ${ }^{23}$, A. Neto ${ }^{30,40}$, R. $\mathrm{Neu}^{49}$, O. Neubauer ${ }^{29}$, M. Newman ${ }^{3}$, K.J. Nicholls ${ }^{3}$, D. Nicolai ${ }^{29}$, T. Nicolas ${ }^{4}$, P. Nieckchen ${ }^{25}$, P. Nielsen ${ }^{7}$, M.P.S. Nightingale ${ }^{3}$, E. Nilsson ${ }^{4}$, D. Nishijima ${ }^{83}$, C. Noble $^{3}$, M. Nocente ${ }^{81}$, D. Nodwell ${ }^{3}$, H. Nordman ${ }^{11}$, I. Nunes ${ }^{40}$, B. O'Meara ${ }^{3}$, M. Oberkofler ${ }^{49}$, B. Obryk ${ }^{36}$, T. Odupitan ${ }^{3}$, M.T. Ogawa ${ }^{43}$, T. O' Gorman ${ }^{3}$, M. Okabayashi ${ }^{59}$, S. Olariu ${ }^{67}$, M. O’Mullane ${ }^{14}$, J. Ongena ${ }^{47}$, F. Orsitto ${ }^{74}$, B.I. Oswuigwe ${ }^{3}$,

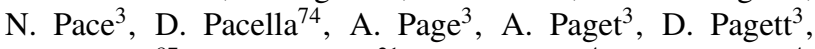
E. Pajuste ${ }^{87}$, S. Palazzo ${ }^{21}$, J. Pamela ${ }^{4}$, S. Pamela ${ }^{4}$, A. Panin $^{29}$, S. Panja ${ }^{34}$, P. Papp ${ }^{13}$, V. Parail ${ }^{3}$, P. Paris ${ }^{90}$, S.C.W. Parish ${ }^{3}$, M. Park ${ }^{52}$, A. Parsloe ${ }^{3}$, R. Pasqualotto ${ }^{7}$, I.J. Pearson ${ }^{3}$, M.A. Pedrosa ${ }^{46}$, R. Pereira ${ }^{40}$, E. Perelli Cippo ${ }^{33}$, Ch. Perez von Thun ${ }^{49}$, C. Perez-Von-Thun ${ }^{26}$, V. PericoliRidolfini $^{74}$, A. Perona ${ }^{58}$, S. Peruzzo $^{7}$, S. Peschanyi ${ }^{44}$, M. Peterka ${ }^{37}$, P. Petersson ${ }^{31}$, G. Petravich ${ }^{95}$, V. Petržilka ${ }^{37}$, D. Pfefferle ${ }^{23}$, V. Philipps ${ }^{29}$, A. Pietropaolo ${ }^{74}$, M. Pillon ${ }^{74}$, G. Pintsuk ${ }^{29}$, P. Piovesan ${ }^{7}$, A. Pires dos Reis ${ }^{39}$, A. Pironti ${ }^{88}$, F. Pisano ${ }^{12}$, R. Pitts ${ }^{42}$, C. Plusczyk ${ }^{44}$, V. Plyusnin ${ }^{40}$, N. Pomaro ${ }^{7}$, O. Pompilian ${ }^{69}$, P.J. Pool ${ }^{3}$, S. Popovichev ${ }^{3}$, F. Porcelli ${ }^{58}$, C. Porosnicu ${ }^{69}$, M. Porton ${ }^{3}$, A. Pospieszczyk ${ }^{29}$, G. Possnert ${ }^{15}$, S. Potzel $^{49}$, T. Powell ${ }^{3}$, K. Pozniak ${ }^{36}$, J. Pozzi $^{3}$, V. Prajapati ${ }^{34}$, R. Prakash ${ }^{34}$, G. Prestopino ${ }^{79}$, D. Price ${ }^{3}$, R. Price ${ }^{3}$, P. Prior $^{3}$, R. Prokopowicz ${ }^{36}$, R. Proudfoot ${ }^{3}$, P. Puglia ${ }^{39}$, M.E. Puiatti ${ }^{7}$, D. Pulley ${ }^{3}$, K. Purahoo ${ }^{3}$, Th. Pütterich ${ }^{49}$, A. Quercia ${ }^{88}$, E. Rachlew ${ }^{17}$, M. Rack ${ }^{29}$, J. Raeder ${ }^{25}$, M.S.J. Rainford ${ }^{3}$, G. Ramogida ${ }^{74}$, S. Ranjan ${ }^{34}$, J. Rasmussen ${ }^{66}$, J.J. Rasmussen ${ }^{66}$, K. Rathod ${ }^{34}$, G. Rattá ${ }^{46}$, C. Rayner ${ }^{3}$, M. Rebai ${ }^{33,81}$, D. Reece ${ }^{3}$, A. Reed ${ }^{3}$, D. Réfy ${ }^{95}$, B. $\operatorname{Regan}^{3}$, J. Regana ${ }^{25}$, M. Reich ${ }^{49}$, P. $\operatorname{Reid}^{3}$, M. Reinelt ${ }^{49}$, M.L. Reinke ${ }^{92}$, M. Reinke ${ }^{56}$, D. Reiser ${ }^{29}$, D. Reiter ${ }^{29}$, D. Rendell ${ }^{3}$, C. Reux ${ }^{4}$, V. Riccardo ${ }^{3}$, F.G. Rimini ${ }^{3}$, M. Riva ${ }^{74}$, J.E.C. Roberts ${ }^{3}$, R.J. Robins ${ }^{3}$, S.A. Robinson ${ }^{3}$, T. Robinson ${ }^{3}$, D.W. Robson ${ }^{3}$, P. Roddick ${ }^{3}$, R. Rodionov ${ }^{72}$, V. Rohde ${ }^{49}$, F. Romanelli ${ }^{74}$, M. Romanelli ${ }^{3}$, S. Romanelli ${ }^{3}$, A. Romano ${ }^{74}$, D. Rowe ${ }^{3}$, S. Rowe ${ }^{3}$, A. Rowley ${ }^{3}$, M. Rubel $^{31}$, G. Rubinacci ${ }^{88}$, L. Ruchko ${ }^{39}$, M. Ruiz ${ }^{78}$, C. Ruset ${ }^{69}$, L. Ryćc ${ }^{36}$, J. Rzadkiewicz ${ }^{36}$, S. Saarelma ${ }^{3}$, R. Sabot ${ }^{4}$, S. Sadakov ${ }^{29}$, E. Safi ${ }^{85}$, P. Sagar ${ }^{3}$, G. Saibene ${ }^{30}$, F. SaintLaurent $^{4}$, M. Salewski66, A. Salmi ${ }^{94}$, F. Salzedas ${ }^{40}$, U. Samm $^{29}$, D. Sandiford ${ }^{3}$, P. Sandquist ${ }^{11}$, P. Santa ${ }^{34}$, M.I.K. Santala ${ }^{1}$, F. Sartori ${ }^{30}$, R. Sartori ${ }^{30}$, R. Saunders ${ }^{3}$, O. Sauter ${ }^{23}$, R. Scannell ${ }^{3}$, A. Scarabosio ${ }^{49}$, T. Schlummer ${ }^{29}$, V. Schmidt ${ }^{7}$, O. Schmitz ${ }^{29}$, S. Schmuck ${ }^{3,50}$, M. Schneider ${ }^{4}$, M. Scholz ${ }^{36}$, K. Schöpf ${ }^{86}$, B. Schweer ${ }^{29}$, G. Sergienko ${ }^{29}$, A. $\operatorname{Serikov}^{44}$, M. $\operatorname{Sertoli}^{49}$, A. Shabbir ${ }^{10}$, M. Shannon ${ }^{25}$, M.M.J. Shannon ${ }^{3}$, S.E. Sharapov ${ }^{3}$, I. Shaw ${ }^{3}$, S.R. Shaw ${ }^{3}$, A. Shepherd $^{3}$, A. Shevelev ${ }^{41}$, A. Shumack ${ }^{28}$, M. Sibbald ${ }^{3}$, B. Sieglin ${ }^{49}$, C. Silva ${ }^{40}$, P.A. Simmons ${ }^{3}$, A. Sinha ${ }^{34}$, S.K. Sipilä ${ }^{1}$ A.C.C. $\operatorname{Sips}^{27}$, P. $\operatorname{Sirén}^{94}$, A. Sirinellit ${ }^{42}$, H. Sjöstrand ${ }^{15}$, M. Skiba ${ }^{15}$, R. Skilton ${ }^{3}$, B. Slade ${ }^{3}$, N. Smith $^{3}$, P.G. Smith ${ }^{3}$, T.J. Smith ${ }^{3}$, L. Snoj ${ }^{63}$, S. Soare ${ }^{68}$, E.R. Solano ${ }^{26,46}$, S. Soldatov ${ }^{10}$, P. Sonato $^{7}$, A. Sopplesa ${ }^{7}$, J. Sousa ${ }^{40}$, C.B.C. Sowden ${ }^{3}$, C. Sozzi ${ }^{33}$, A. Sparkes ${ }^{3}$, T. Spelzini ${ }^{3}$, F. Spineanu ${ }^{69}$, G. Stables ${ }^{3}$, I. Stamatelatos ${ }^{54}$, M.F. Stamp ${ }^{3}$, V. Stancalie ${ }^{69}$, R. Stankiewicz ${ }^{36}$, G. Stankūnas ${ }^{48}$, M. Stano ${ }^{13}$, C. Stan-Sion ${ }^{67}$, D.E. Starkey ${ }^{3}$, M.J. Stead ${ }^{3}$, M. Stejner ${ }^{66}$, A.V. Stephen ${ }^{3}$, M. Stephen ${ }^{34}$, B.D. Stevens ${ }^{3}$, D. Stoyanov ${ }^{35}$, J. Strachan ${ }^{59}$, P. Strand ${ }^{11}$, M. Stransky ${ }^{11}$, P. Ström ${ }^{31}$, G. Stubbs ${ }^{3}$, W. Studholme ${ }^{3}$, F. Subba ${ }^{58}$, 
H.P. Summers ${ }^{14}$, Y. Sun ${ }^{29}$, J. Svensson ${ }^{50}$, N. Sykes ${ }^{3}$, B.D. Syme $^{3}$, T. Szabolics ${ }^{95}$, G. Szepesi ${ }^{3,33}$, A. Szydlowski ${ }^{36}$, T.T. Suzuki ${ }^{43}$, F. Tabarés ${ }^{46}$, V. Takalo ${ }^{65}$, B. Tál ${ }^{95}$, T. Tala ${ }^{94}$, A.R. Talbot ${ }^{3}$, C. Taliercio ${ }^{7}$, P. Tamain ${ }^{4}$, C. Tame ${ }^{3}$, M. Tardocchi ${ }^{33}$, L. Taroni ${ }^{7}$, K.A. Taylor ${ }^{3}$, G. Telesca ${ }^{10}$, N. Teplova ${ }^{41}$, A. Terra ${ }^{29}$, D. Testa ${ }^{23}$, B. Teuchner ${ }^{25}$, S. Tholerus ${ }^{31}$, F. Thomas ${ }^{25}$, J.D. Thomas ${ }^{3}$, P. Thomas ${ }^{42}$, A. Thompson ${ }^{3}$, C.-A. Thompson ${ }^{3}$, V.K. Thompson ${ }^{3}$, L. Thomson ${ }^{3}$, L. Thorne ${ }^{3}$, P.A. Tigwell ${ }^{3}$, N. Tipton ${ }^{3}$, I. Tiseanu ${ }^{69}$, H. Tojo ${ }^{43}$, M.Z. Tokar ${ }^{29}$, M. Tomeš ${ }^{37}$, P. Tonner $^{3}$, S. Tosti ${ }^{74}$, M. Towndrow ${ }^{3}$, P. Trimble ${ }^{3}$, M. Tripsky ${ }^{47}$, M. Tsalas ${ }^{28}$, E. Tsitrone ${ }^{4}$, D. Tskhakaya jun ${ }^{86}$, O. Tudisco ${ }^{74}$, I. Turner $^{3}$, M.M. Turner ${ }^{22}$, M. Turnyanskiy ${ }^{25}$, G. Tvalashvili ${ }^{3}$, S.G.J. Tyrrell ${ }^{3}$, Z. Ul-Abidin ${ }^{3}$, D. Ulyatt ${ }^{3}$, B. Unterberg ${ }^{29}$, H. Urano ${ }^{43}$, I. Uytdenhouwen ${ }^{60}$, A.P. Vadgama ${ }^{3}$, D. Valcarcel $^{3,40}$, M. Valisa ${ }^{7}$, M. Valovic ${ }^{3}$, D. Van Eester ${ }^{47}$, W. Van Renterghem ${ }^{60}$, G.J. van Rooij ${ }^{28}$, C.A.F. Varandas ${ }^{40}$, S. Varoutis ${ }^{44}$, S. Vartanian ${ }^{4}$, K. Vasava ${ }^{34}$, V. Vdovin ${ }^{55}$, J. Vega ${ }^{46}$, G. Verdoolaege ${ }^{10,47}$, R. Verhoeven ${ }^{3}$, C. Verona ${ }^{79}$, M. Vervier ${ }^{47}$, E. Veshchev ${ }^{42}$, D. Vézinet ${ }^{4}$, J. Vicente ${ }^{40}$, S. Villari ${ }^{74}$, F. Villone ${ }^{84}$, I. Vinyar ${ }^{57}$, B. Viola ${ }^{74}$, R. Vitelli ${ }^{79}$, A. Vitins ${ }^{87}$, M. Vlad ${ }^{69}$, I. Voitsekhovitch ${ }^{3,25}$, P. Vondráček ${ }^{37}$, M. Vrancken ${ }^{47}$, W.W. Pires de $\mathrm{Sa}^{39}$, C.W.F. Waldon ${ }^{3}$, M. Walker ${ }^{3}$, M. Walsh ${ }^{42}$, R.J. Warren ${ }^{3}$, J. Waterhouse ${ }^{3}$, N.W. Watkins ${ }^{19}$, C. Watts ${ }^{42}$, T. Wauters ${ }^{47}$, M.W. Way ${ }^{3}$, A. Webster ${ }^{3}$, A. Weckmann ${ }^{31}$, J. Weiland ${ }^{11}$, H. Weisen ${ }^{23}$, M. Weiszflog ${ }^{15}$, S. Welte ${ }^{44}$, J. Wendel ${ }^{44}$, R. Wenninger ${ }^{25,49}$, A.T. West ${ }^{3}$, M.R. Wheatley ${ }^{3}$, S. Whetham ${ }^{3}$, A.M. Whitehead ${ }^{3}$, B.D. Whitehead ${ }^{3}$, P. Whittington ${ }^{3}$, A.M. Widdowson ${ }^{3}$, S. Wiesen ${ }^{29}$, D. Wilkes ${ }^{3}$, J. Wilkinson ${ }^{3}$, M. Williams ${ }^{3}$, A.R. Wilson ${ }^{3}$, D.J. Wilson ${ }^{3}$, H.R. Wilson ${ }^{92}$, M. Wischmeier ${ }^{49}$, G. Withenshaw ${ }^{3}$, D.M. Witts ${ }^{3}$, D. Wojciech ${ }^{36}$, A. Wojeński ${ }^{36}$, D. Wood ${ }^{3}$, S. Wood ${ }^{3}$, C. Woodley ${ }^{3}$, U. Woźnicka $^{36}$, J. Wright $^{3}$, J. $\mathrm{Wu}^{73}$, L. $\mathrm{Yao}^{73}$, D. Yapp ${ }^{3}$, V. Yavorskij ${ }^{86}$, M.G. Yoo ${ }^{62}$, J. Yorkshades ${ }^{3}$, C. Young ${ }^{3}$, D. Young 3 , I.D. Young ${ }^{3}$, W. Zabolotny ${ }^{36}$, J. Zacks ${ }^{3}$, R. Zagorski ${ }^{36}$, F.S. Zaitsev ${ }^{13}$, R. Zanino ${ }^{58}$, V. Zaroschi ${ }^{69}$, K.D. Zastrow ${ }^{3}$, W. Zeidner ${ }^{49}$, A. Ziółkowski ${ }^{36}$, V. Zoita ${ }^{69}$, S. Zoletnik ${ }^{95}$ and I. Zychor ${ }^{36}$ Finland

${ }^{1}$ Aalto University, PO Box 14100, FIN-00076 Aalto,

${ }^{2}$ BCS, Barcelona, Spain

${ }^{3}$ CCFE, Culham Science Centre, Abingdon, Oxon, OX14 3DB, UK

${ }^{4}$ CEA, IRFM, F-13108 Saint Paul Lez Durance, France

${ }^{5}$ Centro Brasileiro de Pesquisas Fisicas, Rua Xavier Sigaud, 160, Rio de Janeiro CEP 22290-180, Brazil

${ }^{6}$ Consorzio CREATE, Via Claudio 21, 80125 Napoli, Italy

${ }^{7}$ Consorzio RFX, corso Stati Uniti 4, 35127 Padova, Italy

${ }^{8}$ Daegu University, Jillyang, Gyeongsan, Gyeongbuk 712-

174, Republic of Korea

${ }^{9}$ Departamento de Física, Universidad Carlos III de Madrid, 28911 Leganés, Madrid, Spain

${ }^{10}$ Department of Applied Physics UG (Ghent University)

St-Pietersnieuwstraat 41 B-9000 Ghent, Belgium

${ }^{11}$ Department of Earth and Space Sciences, Chalmers

University of Technology, SE-41296 Gothenburg, Sweden

${ }^{12}$ Department of Electrical and Electronic Engineering, University of Cagliari, Piazza d'Armi 09123 Cagliari, Italy
${ }^{13}$ Department of Experimental Physics, Faculty of Mathematics, Physics and Informatics, Comenius University, Mlynska dolina F2, 84248 Bratislava, Slovak Republic

${ }^{14}$ Department of Physics and Applied Physics, University of Strathclyde, Glasgow, G4 ONG, UK

${ }^{15}$ Department of Physics and Astronomy, Uppsala University, SE-75120 Uppsala, Sweden

${ }^{16}$ Department of Physics, Lund University, SE-22100 Lund, Sweden

${ }^{17}$ Department of Physics, SCI, KTH, SE-10691 Stockholm, Sweden

${ }^{18}$ Department of Physics, University of Oxford, Oxford OX1 2JD, UK

${ }^{19}$ Department of Physics, University of Warwick, Coventry, CV4 7AL, UK

${ }^{20}$ Department of Pure and Applied Physics, Queens University, Belfast, BT7 1NN, UK

${ }^{21}$ Dipartimento di Ingegneria Elettrica Elettronica e dei Sistemi-Università degli Studi di Catania, 95125 Catania, Italy

${ }^{22}$ Dublin City University (DCU), Dublin, Ireland

${ }^{23}$ Ecole Polytechnique Fédérale de Lausanne (EPFL), CRPP, CH-1015 Lausanne, Switzerland

${ }^{24}$ Ecole Polytechnique, CNRS UMR7648, LPP, F-91128, Palaiseau, France

${ }^{25}$ EUROfusion Programme Management Unit, Boltzmannstr. 2, 85748 Garching, Germany

${ }^{26}$ EUROfusion Programme Management Unit, Culham Science Centre, OX14 3DB Abingdon, UK

${ }^{27}$ European Commission, B-1049 Brussels, Belgium

${ }^{28}$ FOM Institute DIFFER, PO Box 1207, NL-3430 BE Nieuwegein, The Netherlands

${ }^{29}$ Forschungszentrum Jülich GmbH, Institut für Energieund Klimaforschung-Plasmaphysik, 52425 Jülich, Germany

${ }^{30}$ Fusion for Energy Joint Undertaking, Josep Pl. 2, Torres Diagonal Litoral B3, 08019, Barcelona, Spain

${ }^{31}$ Fusion Plasma Physics, EES, KTH, SE-10044 Stockholm, Sweden

${ }^{32}$ General Atomics, PO Box 85608, San Diego, CA 92186-5608, USA

${ }^{33}$ IFP-CNR, via R. Cozzi 53, 20125 Milano, Italy

${ }^{34}$ Institute for Plasma Research, Bhat, Gandhinagar-382 428, Gujarat State, India

${ }^{35}$ Institute of Electronics, Bulgarian Academy of Sciences, 72 Tzarigradsko shosse, Sofia 1784, Bulgaria

${ }^{36}$ Institute of Plasma Physics and laser Microfusion, Hery 23, 01-497 Warsaw, Poland

${ }^{37}$ Institute of Plasma Physics AS CR, Za Slovankou 1782/3, 18200 Praha 8, Czech Republic

${ }^{38}$ Institute of Plasma Physics, Chinese Academy of Sciences, Hefei 230031, People's Republic of China

${ }^{39}$ Instituto de Física, Universidade de São Paulo, Rua do Matão Travessa R Nr.187, CEP 05508-090, Cidade Universitária, São Paulo, Brazil

${ }^{40}$ Instituto de Plasmas e Fusão Nuclear, Instituto Superior Técnico, Universidade de Lisboa, Lisboa, Portugal

${ }^{41}$ Ioffe Physico-Technical Institute, 26 Politekhnicheskaya, St Petersburg 194021, Russian Federation

${ }^{42}$ ITER Organization, Route de Vinon, CS 90 046, 13067 Saint Paul Lez Durance, France 
${ }^{43}$ Japan Atomic Energy Agency, Naka Fusion Research Establishment, Nakamachi, Naka-gun, Ibaraki-ken 311-0913, Japan

${ }^{44}$ Karlsruhe Institute of Technology, PO Box 3640, D76021 Karlsruhe, Germany

${ }^{45}$ Laboratoire J.A. Dieudonné, Université de Nice-SophiaAntipolis, Parc Valrose, F-06108 Nice CEDEX 02, France

${ }^{46}$ Laboratorio Nacional de Fusión, CIEMAT, Madrid, Spain

${ }^{47}$ Laboratory for Plasma Physics, Koninklijke Militaire School-Ecole Royale Militaire, Renaissancelaan 30, Avenue de la Renaissance B-1000, Brussels, Belgium

${ }^{48}$ Lithuanian Energy Institute, Breslaujos g. 3, LT-44403, Kaunas, Lithuania

${ }^{49}$ Max-Planck-Institut für Plasmaphysik, D-85748 Garching, Germany

${ }^{50}$ Max-Planck-Institut für Plasmaphysik, Teilinsitut Greifswald, D-17491 Greifswald, Germany

${ }^{51}$ MIT Plasma Science and Fusion Centre, Cambridge, MA 02139, MA, USA

${ }^{52}$ National Fusion Research Institute (NFRI) 169-148

Gwahak-ro, Yuseong-gu, Daejeon 305-806, Korea

${ }^{53}$ National Technical University of Athens, Iroon

Politechniou 9, 15773 Zografou, Athens, Greece

${ }^{54}$ NCSR 'Demokritos' 153 10, Agia Paraskevi, Attikis, Athens, Greece

${ }^{55}$ NRC Kurchatov Institute, 1 Kurchatov Square, Moscow

123182, Russian Federation

${ }^{56}$ Oak Ridge National Laboratory, Oak Ridge, TN 37831 6169, USA

${ }^{57}$ PELIN LLC, 27a, Gzhatskaya Ulitsa, Saint Petersburg, 195220, Russia

${ }^{58}$ Politecnico di Torino, Corso Duca degli Abruzzi 24, I10129 Torino, Italy

${ }^{59}$ Princeton Plasma Physics Laboratory, James Forrestal Campus, Princeton, NJ 08543, USA

${ }^{60}$ SCK-CEN, Nuclear Research Centre, 2400 Mol, Belgium

${ }^{61}$ Second University of Napoli, Consorzio CREATE, Via Claudio 21, 80125 Napoli, Italy

${ }^{62}$ Seoul National University, Shilim-Dong, Gwanak-Gu, Republic of Korea

${ }^{63}$ Slovenian Fusion Association (SFA), Jozef Stefan Institute, Reactor Physics Department, Jamova 39, SI-1000 Ljubljana, Slovenia

${ }^{64}$ Department of Physics, University of Basel, Basel, Switzerland

${ }^{65}$ Tampere University of Technology, PO Box 527, FI-

33101 Tampere, Finland

${ }^{66}$ Department of Physics, Technical University of Denmark, Bldg 309, DK-2800 Kgs Lyngby, Denmark

${ }^{67}$ The 'Horia Hulubei' National Institute for Physics and Nuclear Engineering, Magurele-Bucharest, Romania

${ }^{68}$ The National Institute for Cryogenics and Isotopic Technology, Ramnicu Valcea, Romania

${ }^{69}$ The National Institute for Laser, Plasma and Radiation Physics, Magurele-Bucharest, Romania

${ }^{70}$ The National Institute for Optoelectronics, MagureleBucharest, Romania

${ }^{71}$ The Nuclear Fuel Plant, Pitesti, Romania
${ }^{72}$ Troitsk Insitute of Innovating and Thermonuclear Research (TRINITI), Troitsk 142190, Moscow Region, Russian Federation

${ }^{73}$ University of Electronic Science and Technology of China, Chengdu, People's Republic of China

${ }^{74}$ Unità Tecnica Fusione-ENEA C.R. Frascati, via E. Fermi 45, 00044 Frascati (Roma), Italy

${ }^{75}$ Universidad Complutense de Madrid, Madrid, Spain

${ }^{76}$ Universidad de Sevilla, Sevilla, Spain

${ }^{77}$ Universidad Nacional de Educación a Distancia, Madrid, Spain

${ }^{78}$ Universidad Politécnica de Madrid, Grupo I2A2, Madrid, Spain

${ }^{79}$ Università di Roma, Rome, Italy

${ }^{80}$ University College Cork (UCC), Corcaigh, Ireland

${ }^{81}$ University Milano-Bicocca, piazza della Scienza 3, 20126 Milano, Italy

${ }^{82}$ University of Basilicata, Consorzio CREATE, Via Claudio 21, 80125 Napoli, Italy

${ }^{83}$ University of California, 1111 Franklin St., Oakland, CA 94607, USA

${ }^{84}$ University of Cassino, Consorzio CREATE, Via Claudio 21, 80125 Napoli, Italy

${ }^{85}$ University of Helsinki, PO Box 43, FI-00014 University of Helsinki, Finland

${ }^{86}$ University of Innsbruck, Fusion@Österreichische Akademie der Wissenschaften (ÖAW), Innsbruck, Austria

${ }^{87}$ University of Latvia, 19 Raina Blvd., Riga, LV 1586, Latvia

${ }^{88}$ University of Napoli 'Federico II', Consorzio CREATE, Via Claudio 21, 80125 Napoli, Italy

${ }^{89}$ University of Napoli Parthenope, Consorzio CREATE,

Via Claudio 21, 80125 Napoli, Italy

${ }^{90}$ University of Tartu, Ülikooli 18, 50090 Tartu, Estonia

${ }^{91}$ University of Texas at Austin, Institute for Fusion Studies, Austin, TX 78712, USA

${ }^{92}$ University of York, Heslington, York YO10 5DD, UK

${ }^{93}$ Vienna University of Technology, Fusion@Österreichische Akademie der Wissenschaften (ÖAW), Vienna, Austria

${ }^{94}$ VTT Technical Research Centre of Finland, PO Box 1000, FIN-02044 VTT, Finland

${ }^{95}$ Wigner Research Centre for Physics, POB 49, H-1525 Budapest, Hungary

\section{References}

[1] Romanelli F. et al 2012 A Roadmap to the Realization of Fusion Energy (Culham, UK: EFDA) ISBN 978-3-00-040720-8

[2] Pamela J. et al 2007 An ITER-like wall for JET J. Nucl. Mater. 363-365 1-11

[3] Pitts R. et al 2011 Physics basis and design of the ITER plasma-facing components J. Nucl. Mater. 415 S957-64

[4] Pitts R.A. et al 2013 A full tungsten divertor for ITER: physics issues and design status J. Nucl. Mater. 438 S48

[5] Matthews G.F. et al 2011 JET ITER-like wall-overview and experimental programme Phys. Scr. 2011014001

[6] Brezinsek S. et al 2011 Overview of experimental preparation for the ITER-like wall at JET J. Nucl. Mater. 415 S936-42

[7] Matthews G.F. et al 2013 Plasma operation with an all metal first-wall: comparison of an ITER-like wall with a carbon wall in JET J. Nucl. Mater. 438 S2-10 
[8] Matthews G.F. et al 2014 The second phase of JET operation with the ITER-like wall Phys. Scr. 2014014015

[9] Brezinsek S. et al 2013 Fuel retention studies with the ITER-like wall in JET Nucl. Fusion 53083023

[10] Loarer T. et al 2013 Comparison of fuel retention in JET between carbon and the ITER like wall J. Nucl. Mater. 438 S 108

[11] Philipps V. et al 2013 Dynamic fuel retention and release under ITER like wall conditions in JET J. Nucl. Mater. 438 S1067

[12] Joffrin E. et al 2014 First scenario development with the JET new ITER-like wall Nucl. Fusion 54013011

[13] Giroud C. et al 2012 Integration of a radiative divertor for heat load control into JET high triangularity ELMy H-mode plasmas Nucl. Fusion $\mathbf{5 2} 063022$

[14] Arnoux G. et al 2014 Power handling of the JET ITER-like wall Phys. Scr. T159 014009

[15] Arnoux G. et al 2012 A protection system for the JET ITER-like wall based on imaging diagnostics Rev. Sci. Instrum. 83 10D727

[16] Järvinen A. et al 2013 Simulations of tungsten transport in the edge of JET ELMy H-mode plasmas J. Nucl. Mater. 438 S 1005

[17] Pütterich T. et al 2013 Observations on the W-transport in the core plasma of JET and ASDEX Upgrade Plasma Phys. Control. Fusion 55124036

[18] Maddison G.P. et al 2014 Contrasting H-mode behaviour with deuterium fuelling and nitrogen seeding in the all-carbon and metallic versions of JET Nucl. Fusion 54073016

[19] Beurskens M.N.A. et al 2014 Global and pedestal confinement in JET with a Be/W metallic wall Nucl. Fusion 54043001

[20] Giroud C. et al 2013 Impact of nitrogen seeding on confinement and power load control of a high-triangularity JET ELMy H-mode plasma with a metal wall Nucl. Fusion 53113025

[21] van Rooij G.J. et al 2013 Tungsten divertor erosion in all metal devices: lessons from the ITER like wall of JET J. Nucl. Mater. 438 S42

[22] Likonen J. et al 2014 First results and surface analysis strategy for plasma-facing components after JET operation with the ITER-like wall Phys. Scr. 2014014016

[23] Heinola K. et al 2014 Tile profiling analysis of samples from the JET ITER-like wall and carbon wall Phys. Scr. 2014014013

[24] Coad J.P. et al 2014 Surface analysis of tiles and samples exposed to the first JET campaigns with the ITER-like wall Phys. Scr. 2014014012

[25] Widdowson A. et al 2014 Material migration patterns and overview of first surface analysis of the JET ITER-like wall Phys. Scr. 2014014010

[26] Coenen J.W. et al 2013 Long-term evolution of the impurity composition and impurity events with the ITER-like wall at JET Nucl. Fusion $\mathbf{5 3} 073043$

[27] Coenen J.W. et al 2013 Evolution of surface melt damage, its influence on plasma performance and prospects of recovery J. Nucl. Mater. 438 S27

[28] Federici G. et al 2003 Assessment of erosion of the ITER divertor targets during type I ELMs Plasma Phys. Control. Fusion 451523

[29] Loarte A. et al 2007 Transient heat loads in current fusion experiments, extrapolation to ITER and consequences for its operation Phys. Scr. 2007222

[30] Coenen J.W. et al 2015 ELM-induced transient tungsten melting in the JET divertor Nucl. Fusion $\mathbf{5 5} 023010$

[31] Corre Y. et al 2014 Heat flux distribution and gyro-radius smoothing effect on misaligned CFC tile in the Tore Supra tokamak Proc. 21st Int. Conf. on Plasma Surface Interactions (Kanazawa, Japan, 26-30 May 2014) P3-086 http://psi2014.nifs.ac.jp/Files/Files/Abstracts/ P3-086_Corre_PSI2014.pdf J. Nucl. Mater. submitted

[32] Dejarnac R. et al 2014 Numerical evaluation of heat flux and surface temperature on a misaligned JET divertor W lamella during ELMs Nucl. Fusion 54123011
[33] Bazylev B. et al 2009 Experimental validation of 3D simulations of tungsten melt erosion under ITER-like transient loads J. Nucl. Mater. 390-391 810-13

[34] Coenen J.W. et al 2014 ELM induced tungsten melting and its impact on tokamak operation Proc. 21st Int. Conf. on Plasma Surface Interactions (Kanazawa, Japan, 26-30 May 2014) http://psi2014.nifs.ac.jp/Files/Files/Abstracts/ I8_Coenen_PS12014.pdf J. Nucl. Mater. submitted

[35] Neu R. et al 2005 Tungsten: an option for divertor and main chamber plasma facing components in future fusion devices Nucl. Fusion 45209

[36] Neu R. et al 2007 Plasma wall interaction and its implication in an all tungsten divertor tokamak Plasma Phys. Control. Fusion 49 B59

[37] Gruber O. et al 2009 Compatibility of ITER scenarios with full tungsten wall in ASDEX Upgrade Nucl. Fusion 49115014

[38] Neu R. et al 2013 Overview on plasma operation with a full tungsten wall in ASDEX Upgrade $J$. Nucl. Mater. 438 S34

[39] Sips A.C. and Gruber O. for the ASDEX Upgrade Team 2008 Compatibility of ITER scenarios with an all-W wall Plasma Phys. Control. Fusion 50124028

[40] Greenwald M. et al 2005 Overview of the Alcator C-Mod program Nucl. Fusion 45 S109

[41] Lipschultz B. et al 2007 Influence of boronization on operation with high-Z plasma facing components in Alcator C-Mod J. Nucl. Mater. 3631110

[42] Lipschultz B. et al 2012 Divertor tungsten tile melting and its effect on core plasma performance Nucl. Fusion 52123002

[43] Brezinsek S. et al 2014 Study of physical and chemical assisted physical sputtering of beryllium in the JET ITER-like wall Nucl. Fusion 54103001

[44] Schmid K. et al 2011 An integrated model of impurity migration and wall composition dynamics for tokamaks J. Nucl. Mater. 415 S284

[45] Schmid K. et al 2014 Quantitative modeling of fuel retention in the JET-C and JET-ILW wall configurations by WallDyn and predictions for ITER Proc. 21st Int. Conf. on Plasma Surface Interactions (Kanazawa, Japan, 26-30 May 2014) http://psi2014.nifs.ac.jp/Files/Files/Abstracts/ I6_Schmid_PSI2014.pdf J. Nucl. Mater. submitted

[46] de Vries P.C. et al 2012 The impact of the ITER-like wall at JET on disruptions Plasma Phys. Control. Fusion 54124032

[47] Lehnen M. et al 2013 Disruption heat loads and their mitigation in JET with the ITER-like wall J. Nucl. Mater. 438 S 102

[48] Lehnen M. et al 2013 Impact and mitigation of disruptions with the ITER-like wall in JET Nucl. Fusion 53093007

[49] Papp G. et al 2013 The effect of ITER-like wall on runaway electron generation in JET Nucl. Fusion 53123017

[50] Reux C. et al 2014 Runaway electron generation with the ITER-like wall and efficiency of massive gas injection at JET Proc. 25th IAEA Fusion Energy Conf. (St Petersburg, Russia, 2014) www-pub.iaea.org/MTCD/Meetings/ PDFplus/2014/cn221/cn221ConferenceProgrammeAnd Abstracts.pdf

[51] Reux C. et al 2014 Runaway beam studies during disruptions at JET-ILW Proc. 21st Int. Conf. on Plasma Surface Interactions (Kanazawa, Japan, 26-30 May 2014) http://psi2014.nifs.ac.jp/Files/Files/Abstracts/ I19_Reux_PSI2014.pdf J. Nucl. Mater. submitted

[52] Nunes I. et al Compatibility of high performance operation with JET ILW Proc. 25th IAEA Fusion Energy Conf. (St Petersburg, Russia, 2014) www-pub.iaea.org/MTCD/ Meetings/PDFplus/2014/cn221/cn221Conference ProgrammeAndAbstracts.pdf

[53] Joffrin E. et al 2014 Impact of divertor geometry on ITER scenarios performance in the JET metallic wall Proc. 25th IAEA Fusion Energy Conf. (St Petersburg, Russia, 
2014) www-pub.iaea.org/MTCD/Meetings/PDFplus/2014/ $\mathrm{cn} 221 / \mathrm{cn} 221 \mathrm{ConferenceProgrammeAndAbstracts.pdf}$

[54] ITER Physics Basis 1999 Nucl. Fusion 392175

[55] Beurskens M.N.A. et al 2013 The effect of a metal wall on confinement in JET and ASDEX Upgrade Plasma Phys. Control. Fusion 55124043

[56] Luce T. et al 2008 Application of dimensionless parameter scaling techniques to the design and interpretation of magnetic fusion experiments Plasma Phys. Control. Fusion 50043001

[57] Challis C.D. et al Improved confinement in JET high $\beta$ plasmas with an ITER-like wall Nucl. Fusion submitted (arXiv:1501.03929)

[58] Joffrin E. et al 2014 Role of neutrals on the confinement of hybrid scenario in JET-C and JET-ILW Proc. 41 st EPS Conf. on Plasma Physics (Berlin, Germany, 2014) http://ocs.ciemat.es/EPS2014PAP/pdf/O4.125.pdf

[59] Garcia J. et al. 2014 Core microturbulence and edge MHD interplay and stabilization by fast ions in tokamak confined plasmas Proc. 25th IAEA Fusion Energy Conf. (St Petersburg, Russia. 2014) www-pub.iaea.org/MTCD/ Meetings/PDFplus/2014/cn221/cn221Conference ProgrammeAndAbstracts.pdf

[60] Citrin J. et al 2013 Nonlinear stabilization of tokamak microturbulence by fast ions Phys. Rev. Lett. 111155001

[61] Angioni C. et al 2009 Particle transport in tokamak plasmas, theory and experiment Plasma Phys. Control. Fusion 51124017

[62] Maggi C. et al 2014 Confinement and stability of the edge pedestal in JET ELMy H-mode scenarios with the ITER-like wall Proc. 25th IAEA Fusion Energy Conf. (St Petersburg, Russia, 2014) www-pub.iaea.org/MTCD/ Meetings/PDFplus/2014/cn221/cn221Conference ProgrammeAndAbstracts.pdf
[63] Angioni C. et al 2014 Tungsten transport in JET H-mode plasmas in hybrid scenario, experimental observations and modelling Nucl. Fusion 54083028

[64] Lerche E. et al 2014 ICRH for mitigation of core impurity accumulation in JET-ILW Proc. 25th IAEA Fusion Energy Conf. (St Petersburg, Russia, 2014) www-pub.iaea.org/ MTCD/Meetings/PDFplus/2014/cn221/cn221Conference ProgrammeAndAbstracts.pdf

[65] Van Eester D. et al 2013 Ion cyclotron resonance heating-induced density modification near antennas Plasma Phys. Control. Fusion 55025002

[66] Van Eester D. et al 2013 Connection coefficients for cold plasma wave propagation near metallic surfaces Plasma Phys. Control. Fusion 55055001

[67] Wischmeier M. et al 2014 Impurity seeding on JET to achieve power plant like divertor conditions Proc. 25th IAEA Fusion Energy Conf. (St Petersburg, Russia, 2014) www-pub.iaea.org/MTCD/Meetings/PDFplus/2014/ cn221/cn221ConferenceProgrammeAndAbstracts.pdf

[68] Giroud C. et al 2015 Progress at JET in integrating ITER-relevant core and edge plasmas within the constraints of an ITER-like wall Plasma Phys. Control. Fusion 57035004

[69] Budny R. et al 2014 private communication

[70] Delabie E. et al 2014 Overview and interpretation of $\mathrm{L}-\mathrm{H}$ threshold experiments on JET with the ITER-like wall Proc. 25th IAEA Fusion Energy Conf. (St Petersburg, Russia, 2014) www-pub.iaea.org/MTCD/Meetings/PDFplus/2014/ cn221/cn221ConferenceProgrammeAndAbstracts.pdf

[71] Maggi C.F. et al $2014 \mathrm{~L}-\mathrm{H}$ power threshold studies in JET with Be/W and C wall Nucl. Fusion 54023007

[72] Snyder P.B. et al 2011 A first-principles predictive model of the pedestal height and width: development, testing and ITER optimization with the EPED model Nucl. Fusion 51103016 